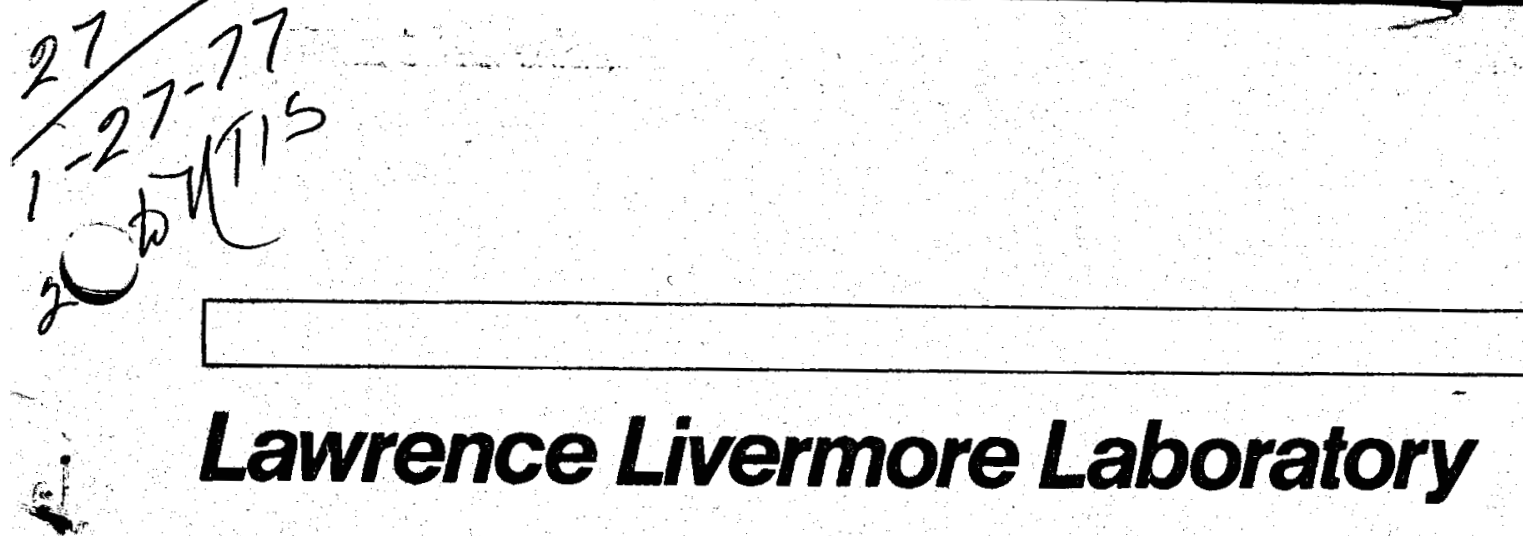

GENERAL, CHEMISTRY DIVISION QUARTERLY REPORT

July through September 1976

Compiled and edited by J. E. Harrar

December 9, 1976

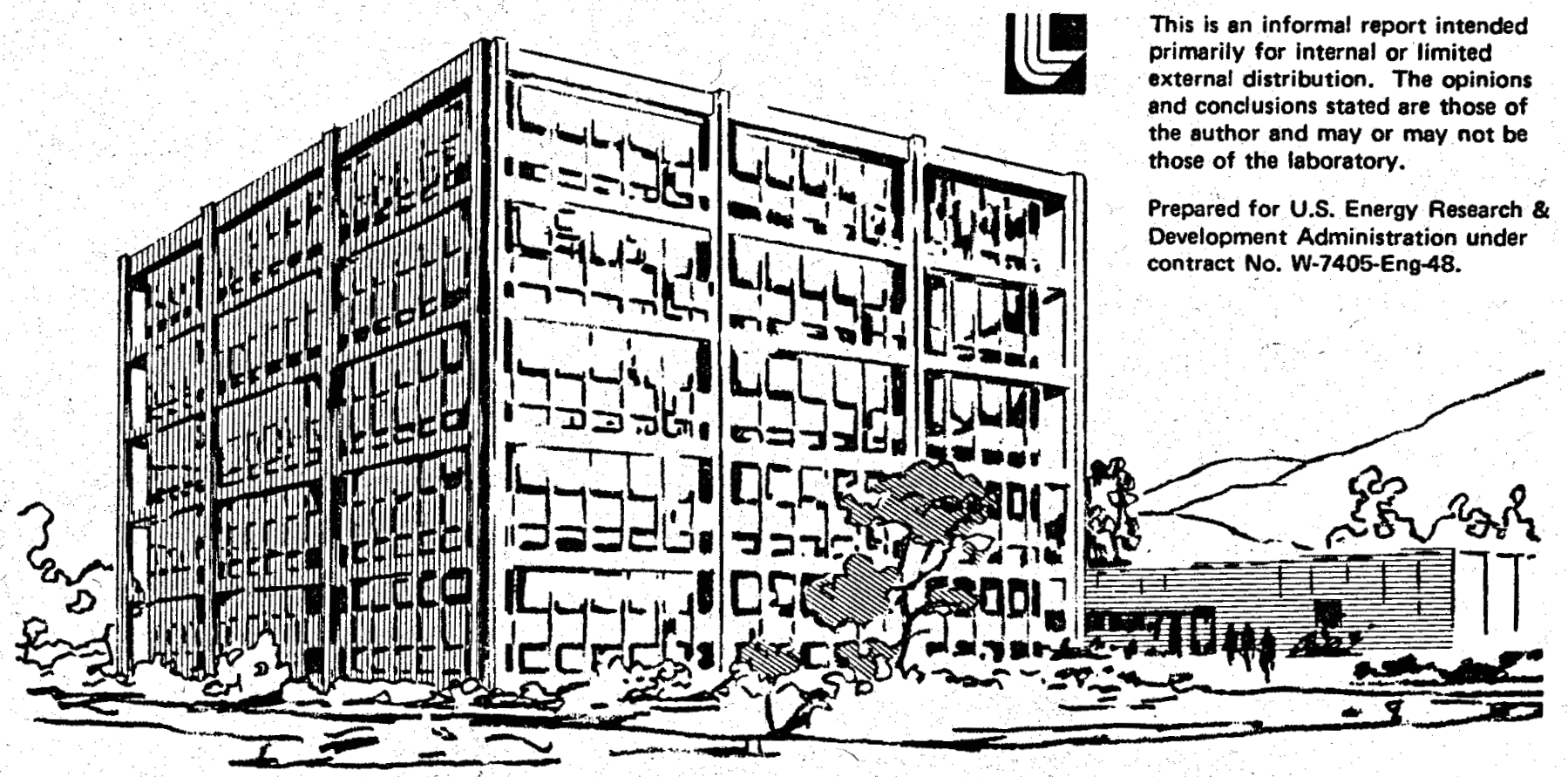




\section{DISCLAIMER}

This report was prepared as an account of work sponsored by an agency of the United States Government. Neither the United States Government nor any agency Thereof, nor any of their employees, makes any warranty, express or implied, or assumes any legal liability or responsibility for the accuracy, completeness, or usefulness of any information, apparatus, product, or process disclosed, or represents that its use would not infringe privately owned rights. Reference herein to any specific commercial product, process, or service by trade name, trademark, manufacturer, or otherwise does not necessarily constitute or imply its endorsement, recommendation, or favoring by the United States Government or any agency thereof. The views and opinions of authors expressed herein do not necessarily state or reflect those of the United States Government or any agency thereof. 


\section{DISCLAIMER}

Portions of this document may be illegible in electronic image products. Images are produced from the best available original document. 
CONTENTS

Analytical Research and Development for the Whitney Program . . . . . . 1 Automation and Instrumentation .................. 1

Computer Controlled Burets . . . . . . . . . . . . 1

Measurement of Vapor Pressures . . . . . . . . . 4

Analytical Methodology and Measurements . . . . . . . . 6

The Ion Etch Rate of Carbon-Bearing Materials in the ESCA Spectrometer . . . . . . . . . . . . . 6

Luminescence Studies of Oxygen Adsorption on Thorium . . . . 10

Actinide Spectroscopy . . . . . . . . . . . . . . 14

Accurate Determination of the Internal Diameter of a Hollow Sphere . . . . . . . . . . . . . . . 16

An Infrared Method for Determining 1,3,5-Triazido-2,4,6trinitrobenzene (TATNB) in Benzotrisfuroxan (BTF) . . . . 17

Determination of Hydroxyl in Polyols . . . . . . . . . 20

Analysis of Explosive Composites . . . . . . . . . 22

Study of a New Potassium-Ion Selective Electrode . . . . . . 24

Lower Limits of the Potentlometric Titration of Perchlorate Ion-Selective Electrode . . . . . . . . . . . . . 26

Characterization of a Pulse-Pumped Dye Laser . . . . . . . 27

Laser-Induced Molecular Fluorescence . . . . . . . . . 29

The Effect of Stress on the Fluorescence of Kevlar Fiber - . 32

New Method for the Determination of Luminescence Lifetimes by Using the Beat Noise of a CW Laser as a Multifrequency Modulated Source . . . . . . . . . . 34

Development of Analytical Methods for the Energy Program . . . . . . . 37 Geothermal Brine and Solids Characterization . . . . . . . . . . 37 Continuous Water Monitor for Oil-Shale Retort Effluent . . . . . . 40 


\title{
ANALYTICAL RESEARCH AND DEVELOPMENT FOR THE
} WHITNEY PROGRAM

\author{
AUTOMATION AND INSTRUMENTATION \\ Computer-Controlled Burets
}

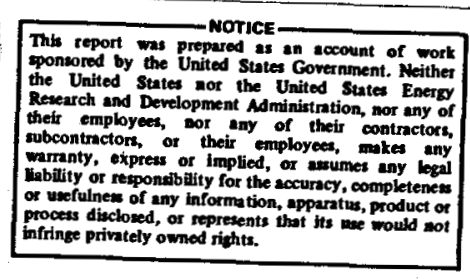

Responsible Personnel: W. G. Boyle

Brief Description:

A previously described ${ }^{1} 10-\mathrm{cm}^{3}$, computer-controlled buret with a modified sidearm has been fitted with a new type of piston and recalibrated using a modified calibration procedure.

Status: Our computer-controlled dispensing dilution system uses a Mettler DV-10 buret drive with a modified $10-\mathrm{cm}^{3}$ Mettler buret and an LLL-built buret drive with a $50-\mathrm{cm}^{3}$ Mettler buret. ${ }^{2}$ A PDP-8/e computer using programs written in modified FOCAL ${ }^{3}$ controls the dispenser-dilutor.

One of the problems associated with dispensing liquids by means of Teflon piston-type burets is the formation of air bubbles on the surface of the piston. We recently replaced the old piston in the $10-\mathrm{cm}^{3}$ buret with a new type of Teflon piston with a deep inset. Preliminary experiments showed that air-bubble formation was very much reduced and that very precise deliveries could be made. Since the new piston effectively changed the location of the volume traversed during dispensing, new calibrations were necessary. The entire calibration program was then re-examined to see if it could be improved.

The program helps the operator calibrate the buret. It first refills the buret and expels a drop from the tip to ensure that the buret tip is ful1. The program then asks for a volume (in $\mathrm{ml}$ ) to be dispensed. The operator enters the volume at the keyboard and the computer looks up in a table (acquired from previous calibrations) the number of steps to be used to drive the buret stepping motor.

After the initial drop on the buret tip is touched off, a tared weighing bottle is positioned under the buret and the computer begins the

1. Analytical Chemistry Quarterly Report, October through December 1972 , Lawrence Livermore Laboratory, Rept. UCID-15644-72-4 (1973), p. 1.

2. Analytical Chemistry Quarterly Report, April through June 1973, Lawrence Livermore Laboratory, Rept. UCID-15644-73-2 (1973), p. 2.

3. Analytical Chemistry Quarterly Report, January through March 1973, Lawrence Livermore Laboratory, Rept. UCID-15644-73-1 (1973), p. 41. 
delivery. After delivery, the last drop is touched off into the weighing bottle. The operator then weighs the water on an analytical balance to the nearest $0.1 \mathrm{mg}$ and enters the weight and density at the computer. The computer calculates the actual volume delivered and a new value $\left(\mathrm{cm}^{3} / \mathrm{step}\right)$ that should be used for the new calibration table.

Careful comparison between the volume counter on the Mettler buret drive and the steps that the computer indicated would be used, showed that a minimum time of $6 \mathrm{~ms}$ between steps was required to enable the computer to keep up with the buret drive. It was also found in some cases that there had not been time for the valve to open so that the buret attempted to operate against closed valves for the first few steps. The time allowed for valve operation was therefore doubled.

When the initial operation of the buret was carried out at $6 \mathrm{~ms}$ between steps, and a small volume was expelled to initialize the buret before an actual delivery, the drop would sometimes tear off at the end of delivery and leave part of the buret tip unfilled. This problem was solved by expelling the initial drop at a time of $50 \mathrm{~ms}$ between steps. When this was done we found that there was a $0.05 \mathrm{~cm}^{3}$ dead volume somewhere in the valve-line linkage. In other words, we saw that although a volume change was indicated there was not any movement of liquid at the buret tip. However, at $0.06 \mathrm{~cm}^{3}$, a drop began to leave the buret tip; this reading was used to start each delivery.

The buret was calibrated at 11 points. Emphasis was placed on the smaller volumes. The Mettler buret stepping motor advances the piston in minimum increments of $0.002 \mathrm{~cm}^{3}$. Thus, the theoretical resolution of the buret $1 \mathrm{~s}$ $0.002 \mathrm{~cm}^{3}$. The results of the calibrations shown in Table 1 reveal that this resolution was easily achieved.

Because of a variation of calibration value with volume delivered, the accuracy of the volume delivered depends on the portion of the buret used. This is seen in Table 1. However, the variation is small for volumes above $1.5 \mathrm{~cm}^{3}$. For accurate deliveries of smaller volumes $\left(<1.5 \mathrm{~cm}^{3}\right)$ using the Initial section of the buret, the calibration intervals would have to be much closer together.

Table 1 shows that the $10-\mathrm{cm}^{3}$ buret could be used to deliver $1-\mathrm{cm}^{3}$ volumes accurately and precisely through most of its capacity without refilling. 
Table 1. Calibration of computer-controlled $10-\mathrm{cm}^{3}$ buret.

\begin{tabular}{llllll}
\hline $\begin{array}{c}\text { Nominal } \\
\text { volume, } \\
\mathrm{cm}^{3}\end{array}$ & $\begin{array}{c}\text { Mean volume } \\
\text { delivered, } \mathrm{cm}^{3}\end{array}$ & $\begin{array}{c}\text { No } \\
\text { of } \\
\text { steps }\end{array}$ & $\begin{array}{c}\text { No. of } \\
\text { calibrations }\end{array}$ & $\begin{array}{c}\text { Mean calibration } \\
\mathrm{cm}^{3} / 10^{3} \text { steps }\end{array}$ & $\begin{array}{c}\text { Standard } \\
\text { dev }\end{array}$ \\
\hline 0.2 & 0.2042 & 206 & 3 & 0.99126 & 0.00128 \\
0.6 & 0.6033 & 609 & 3 & 0.99070 & 0.00041 \\
1.0 & 1.0062 & 1009 & 4 & 0.99718 & 0.00042 \\
1.25 & 1.2513 & 1253 & 3 & 0.99862 & 0.00030 \\
1.5 & 1.5087 & 1512 & 3 & 0.99780 & 0.00060 \\
1.75 & 1.7583 & 1763 & 3 & 0.99732 & 0.00031 \\
2.0 & 2.0087 & 2014 & 6 & 0.99738 & 0.00053 \\
2.75 & 2.7598 & 2766 & 3 & 0.99777 & 0.00025 \\
4.0 & 4.0059 & 4016 & 3 & 0.99749 & 0.00030 \\
5.31 & 5.3144 & 5327 & 3 & 0.99764 & 0.00015 \\
8.31 & 3.3186 & 8335 & 3 & 0.99803 & 0.00006 \\
\hline
\end{tabular}




\section{Measurement of Vapor Pressures}

Responsible Personnel: R. W. Crawford

Brief Description:

Two systems for determining vapor pressure have been built and used. One is based on a Knudsen effusion cell and the other is a static system.

Status: The cholce of a method to measure vapor pressure depends on the magnitude of the pressure. Low vapor pressures $\left(1 \mathrm{~Pa}\right.$ to $5 \times 10^{-7} \mathrm{~Pa}, 10^{-3}$ torr to $10^{-9}$ torr) can be measured nicely by effusion methods. Higher pressures are measured easily by static systems.

A Knudsen-cell effusion system was built and used to measure the vapor pressures of a series of fluorocarbon oils at $65^{\circ} \mathrm{C}$. The cell is aluminum, and is $1.2-\mathrm{cm}$ high by $0.6-\mathrm{cm}$ in diameter. Five different lids having orifices ranging from $0.5 \mathrm{~mm}$ to $2.5 \mathrm{~mm}$ in diameter are available for the cell. The stainless-steel vacuum chamber is mounted in an oven, which is stable to $\pm 0.15^{\circ} \mathrm{C}$ as measured by a quartz digital thermometer.

Using this equipment, we determined a series of vapor pressures ranging from $6 \times 10^{-2} \mathrm{~Pa}$ to $<2 \times 10^{-5} \mathrm{~Pa}\left(4.5 \times 10^{-4}\right.$ to $1.5 \times 10^{-7}$ torr $)$. This apparatus should be capable of measuring vapor pressures as low as $5 \times 10^{-7}$ $\mathrm{Pa}\left(4 \times 10^{-9}\right.$ torr $)$ over a temperature range from 35 to $400^{\circ} \mathrm{C}$. Table 21 sts measurements made at $65^{\circ} \mathrm{C}$.

Table 2. Vapor pressures of fluorocarbon oils.

\section{Vapor Pressure}

Material

$\mathrm{Pa}$

torr

Halocarbon $10-25$

$5 \times 10^{-2}$

MCS-210

Fomblin $\mathrm{Y}-25$

Krytox $143 \mathrm{AC}$

Krytox $143 \mathrm{AD}$
$3 \times 10^{-4}$

$3 \times 10^{-4}$

$3 \times 10^{-5}$

$<4 \times 10^{-5}$
$4 \times 10^{-4}$

$2 \times 10^{-6}$

$2 \times 10^{-6}$

$2 \times 10^{-7}$

$<3 \times 10^{-7}$ 
A static system was used to measure the vapor pressure of naphthalene. Pressure measurements were made with a variable capacitance transducer with a full-scale rating of $133 \mathrm{~Pa}$ ( 1 torr). The rest of the system was clean, bakeable stainless steel and designed for minimum volume and maximum conductance. The system was not contained in a thermostated chamber, so accuracy of the measurement was poor. A chamber designed to maintain ambient and subambient temperatures will be designed or purchased to improve future measurements. 


\section{ANALYTICAL METHODOLOGY AND MEASUREMENTS}

\section{The Ion Etch Rate of Carbon-Bearing}

Materials in the ESCA Spectrometer

Responsible Personnel: J. W. Fischer and R. G. Meisenheimer

Brief Description:

The ion etch rate for carbon-rich materials has been determined empirically using erythrocyte membranes.

Status: Low-energy argon Lons are commonly used to strip away successive atom layers from a solid surface to facilitate depth profiling by various surface analytical techniques such as $x$-ray photoelectron spectroscopy and Auger spectroscopy. Accurate depth profiling requires precise knowledge of the ion etch rates, or more fundamentally, the ion current density and the sputter yields. The following equation expresses the etch rate for a given material:

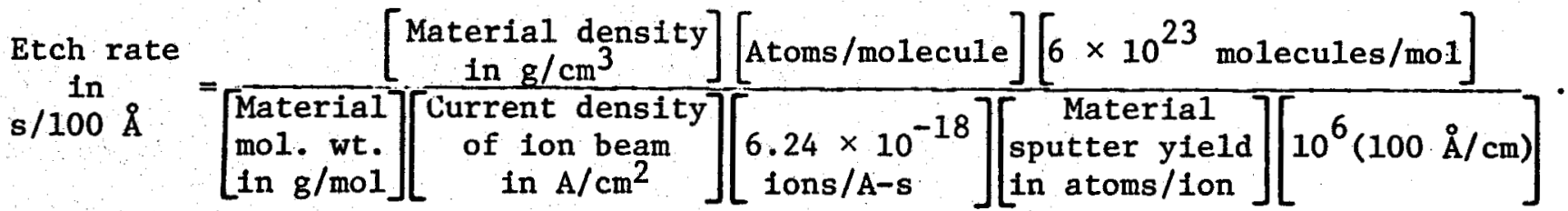

The ion gun currently in use on the Hewlett-Packard ESCA spectrometer is a Physical Electronics model 04-131F, which has a current density under normal conditions of $25 \mu \mathrm{A} / \mathrm{cm}^{2}$ as calculated from the manufacturer's data. Inserting this value in the above equation, we find:

$$
\underset{\mathrm{s} / 100 \AA}{\text { Etch rate }}=\frac{\left.(3850) \text { (density in } \mathrm{g} / \mathrm{cm}^{3}\right)(\text { atoms } / \mathrm{molecule})}{(\mathrm{mol.} \text { wt. in } \mathrm{g} / \mathrm{mol})(\text { sputter yleld in atoms/ion) }}
$$

Values for the sputter ylelds are usually taken or extrapolated from tables found in the ilterature. 4

The results of our studies on human erythrocyte membranes were reported previously 5,6 These studies involved argon ion etching of the erythrocyte membranes. In that work we calculated an etch rate using the sputter yleld

4. G. Carter and J. S. Colligon, Ion Bombardment of Solids (American Elsevier Pub. Co., 1968) and G. K. Wehner, General Mil1s, Rept. No. 2309 (1962).

5. General Chemistry Division Quarterly Report, Apri1 through June 1975, Lawrence Livermore Laboratory, Rept. UCID-15644-75-2, p. 38 .

6. R. G. Meisenheimer, J. W. Fischer, and S. J. Rehfeld, Biochemical and Biophysical Research Communications, 68, 994 (1976). 
for pure carbon as a substitute for that of the cellular material involved. Using the above equation, we calculated a sputter etch rate of $30 \mathrm{~min} / 100 \AA$.

To more accurately determine the etch rate for this type of material, we collected a normal erythrocyte sample in a heparinized polypropylene tube and centrifuged at $3000 \mathrm{~g}$ for $30 \mathrm{~min}$ at $4^{\circ} \mathrm{C}$ to separate plasma and white cells. After this treatment interstitial fluid accounted for only $1 \%$ of the cell sample. After centrifuging, the plasma and one-third of the upper layer of packed red cells were removed to insure adequate removal of the white cells. This material was evaporated to dryness at room temperature and pressure.

The resulting material was ground in a mortar and pestle and the powder pressed into a standard ESCA pellet. A 200-mesh gold transmission electron microscope grid was placed over the pellet, and the pellet with the attached gold grid was argon-1on etched in the ESCA spectrometer for $28.25 \mathrm{~h}$ with 940-V argon Ions at the current density previously discussed. The etched erythrocyte pellet was removed from the spectrometer and was coated with $\sim 500 \AA$ of gold in a vacuum evaporator. The pellet was then examined in the scanning electron microscope and a series of photomicrographs were taken. A copy of one of these photomicrographs taken at a magnification of 15000 and at an angle of $45 \mathrm{deg}$, is shown in Fig. 1.

A portion of the pellet exposed to the ion beam is clearly visible at the bottom of the photomicrograph while a section of the pellet protected from the beam by the presence of the gold grid is apparent at the top of the picture. The sharp vertical edge created by the interface between the etched and unetched surfaces of the pellet is quite apparent. The height of this vertical edge 1s, of course, a measure of the amount of materlal removed during the $28.25-h$ etch. The actual helght of the vertical edge, or the depth of etch, is given by

Depth of etch $=\frac{\left[\begin{array}{l}\text { Height of vertical edge } \\ \text { In cm as measured on the } \\ \text { photo }\end{array}\right]\left[10^{8} \AA / \mathrm{cm}\right]}{(\cos 45 \mathrm{deg})\left(1.5 \times 10^{4}\right)}=4.7 \times 10^{3} \AA$

where the measured height of the vertical edge on the phota is nominally 0.5 cm. Thus the etch rate for the erythrocyte pellet is given by

$$
s / \AA=\frac{(28.25 \mathrm{~h})(3600 \mathrm{~s} / \mathrm{h})}{4.7 \times 10^{3} \AA}
$$




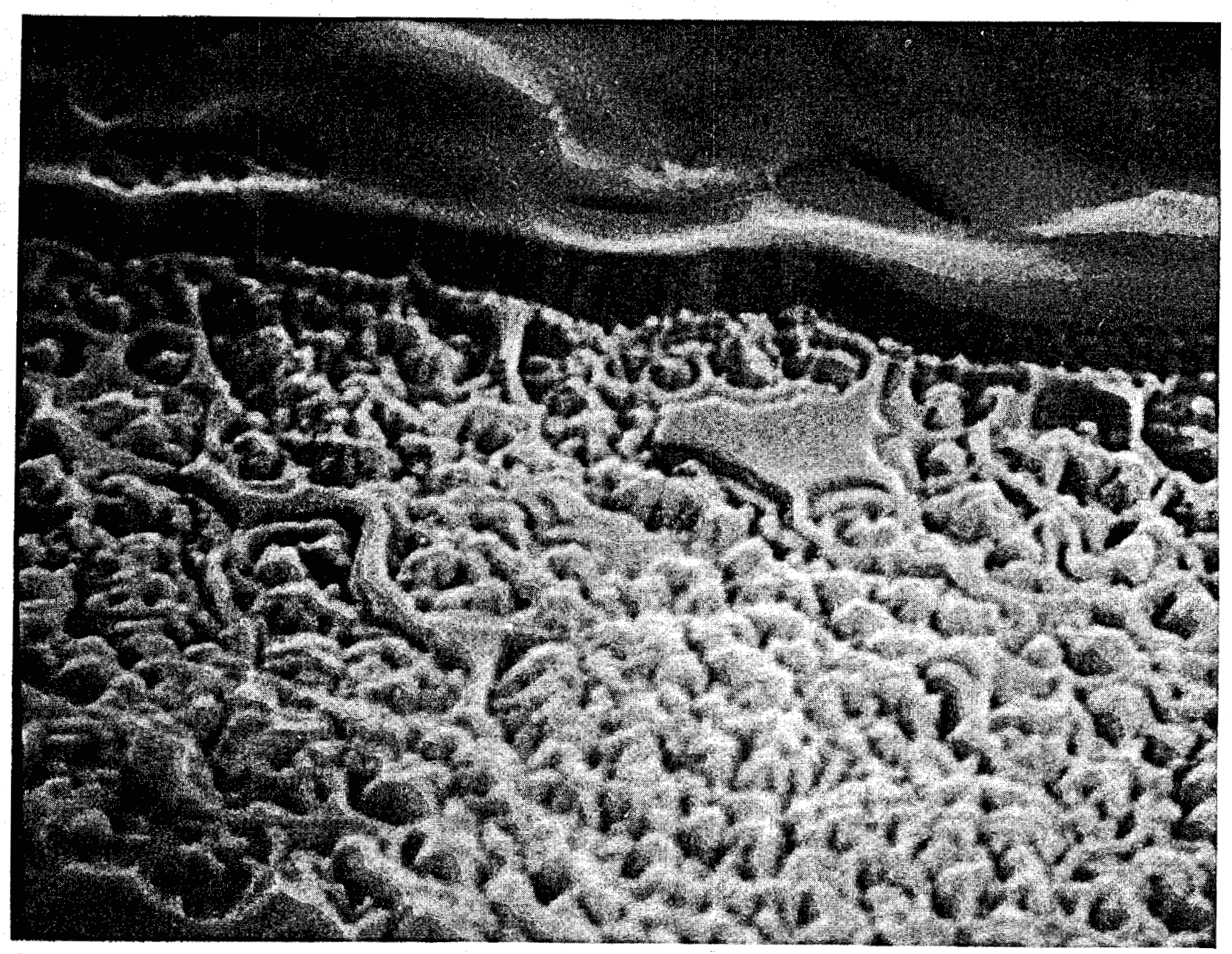

Fig. 1. Photomicrograph of an etched erythrocyte pellet. 15 000x. 
This yields a value of $36 \mathrm{~min}$ per $100 \AA$ for the etch rate. We see from this calculation that our previous etch-rate calculation for erythrocyte membranes, based on the sputter yields for carbon, was in excellent agreement with the experimental results described above.

This empirlcal technique will be applied to other carbon-rich systems to determine the effect of various types of carbon-carbon bonds on the sputter yields. 


\title{
Luminescence Studies of Oxygen Adsorption on Thorium
}

\author{
Responsible Personne1: R. Bastasz, ${ }^{*}$ C. A. Colmenares, G. A. Somorjai, ${ }^{\dagger}$ \\ and $R$. L. Smith ${ }^{*}$
}

Brief Description: The Interaction of oxygen with a thorium metal surface is being studied by monitoring the luminescence of thorium in an electron beam. By combining luminescence measurements with Auger electron spectroscopy data, it is possible to distinguish between processes that depend upon the oxygen pressure at the sample surface, and those that depend only upon the amount of adsorbed oxygen.

Status: The corrosion rates of metals are usually controlled by reactions occurring on their surfaces. The oxidation of thorium by oxygen is one example of such a process. We are studying this reaction to give us a better understanding of its mechanism and those of the oxidations of the actinides in general. With this knowledge it should be possible to modify the surfaces of thorium and other actinides to inhibit corrosion.

When an electron beam strikes a sample of thorium metal, a blue luminescence can be observed. The intensity of this luminescence is affected by gases adsorbed on the sample surface, and we have used this phenomenon to study the mechanism of oxygen adsorption on thorium.

A sample of high-purity thorfum metal was positioned inside a vacuum chamber, which could be evacuated to $25 \mathrm{nPa}$, so that it intersected the paths of a $3-\mathrm{keV}$ electron beam and an $\mathrm{Ar}^{+}$ion beam. The surface of the sample could also be viewed through a window in the chamber. An external telephotometer was focused on the spot at the sample surface where the electron beam impinged and used to monitor the luminosity of the sample in the electron beam. After cleaning the sample using the $\mathrm{Ar}^{+}$Ion beam, the chamber was filled to a low pressure $(10 \mu \mathrm{Pa})$ with oxygen and changes in the luminosity were recorded. During this time it was also possible to gather Auger spectra in order to determine the elemental composition of the sample surface.

\footnotetext{
* Participating guest from Lawrence Berkeley Laboratory, Berkeley, CA.

LBL and Department of Chemistry, University of California, Berkeley. ** Research Engineering Division, LLL.
} 
The results of a typical experiment are shown in Fig. 2, which is a record of the sample luminosity, before, during, and after oxygen exposure. At point $A$, before the exposure, the relative Auger signal intensities of 0 and Th were measured. Oxygen was admitted into the chamber at point B and imnediately the sample luminosity began to increase, While the chamber was filled with oxygen, Auger measurements were again made, as indicated at point $C$. The oxygen was pumped out of the chamber at point D. Following pumpout, the sample luminosity, such as at point $E$, was greater than it was before the exposure and less than 1 t was during the exposure. Auger data indicated that oxygen was adsorbed during the exposure and remained adsorbed on the thorium after the gaseous oxygen was pumped out. Duplicate experiments were performed using a stainless steel sample in place of thorfum and demonstrated that the luminosity changes were not extrinsic to the thorium sample.

Considering the luminescence and Auger measurements together allows one to infer that at least two processes, which both produce luminescence, are occurring on the thorium surface. First, one process associated with luminescence is dependent upon oxygen pressure. This can be seen by comparing points $\mathrm{C}$ and $\mathrm{E}$ in Fig. 2. Since the amount of oxygen on the thorium surface, as monitored by Auger spectroscopy, is nearly the same at point $C$ as at point $E$, the difference in Iuminosity must be attributed to the difference in the oxygen pressure at the thorium surface. Second, adsorbed oxygen, which is present in the absence of gas phase oxygen, must also be a contributing factor to the luminescence. This is evident because the luminescence from a cleaned surface (as at point $A$ ) was less intense than the luminescence when Auger data indicated that surface oxygen was present (as at point E).

Suppose that the mechanism for oxygen adsorption on thorium consists of two steps: 1) chemisorption of molecular oxygen from the gas phase and 2) dissociation of molecular oxygen at the surface into monatomic chemisorbed oxygen. As a result both diatomic and monatomic oxygen would be present on the surface. If the dissociation step were essentially irreversible, a situation would arise in which the surface concentration of diatomic oxygen would be determined by the rate of chemisorption of molecular oxygen and by the rate of its dissociation at the surface. A dynamic equilibrium would be established and the surface concentration of diatomic oxygen would be pressure dependent. 


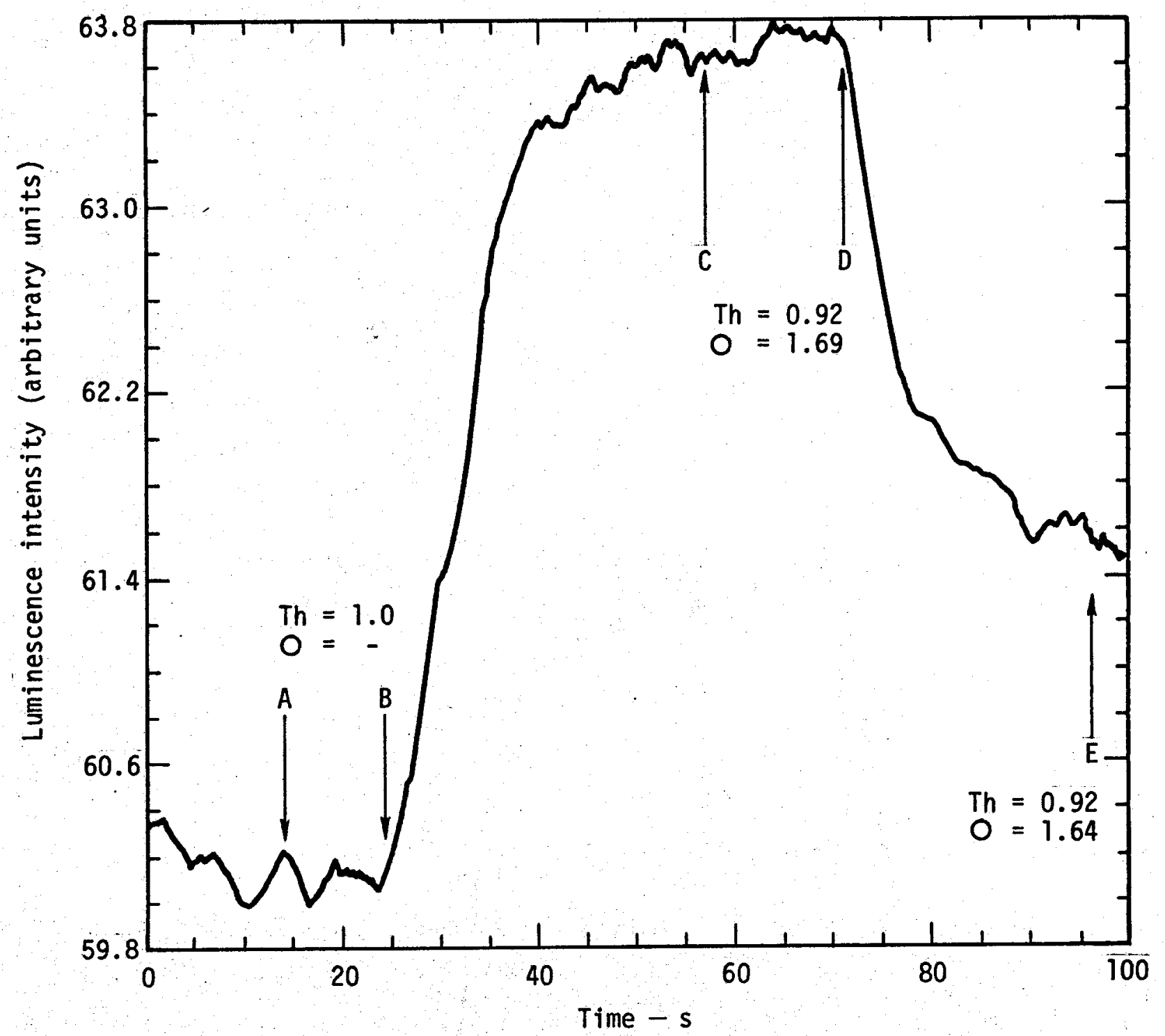

Fig. 2. Thorium luminescence during exposure to oxygen. Auger-signal relative peak to peak intensities for the elements thorium and oxygen are listed at points $A, C$, and $E$. The vacuum chamber was filled to $10 \mu \mathrm{Pa}$ with oxygen at point $\mathrm{B}$ and pumped out at point $\mathrm{D}$. 
This two-step mechanism describes the effects we have observed. The pressure dependence of the luminescence intensity can arise from a process involving diatomic oxygen, such as:

$$
\mathrm{o}_{2} \text { (ads) }+\mathrm{e}^{-} \rightarrow\left(\mathrm{O}_{2}\right)^{-}+\mathrm{O}_{2}+\mathrm{hv}
$$

and the dependence of the luminescence intensity upon the amount of adsorbed oxygen can arise from a process involving monatomic oxygen, such as:

$$
o(\text { ads })+e^{-}\left(0^{-}\right)^{*}+0^{-}+h v \text {. }
$$

The total observed luminescence intensity is the sum of the photons detected from each of the two processes, so that the greatest luminescence intensity occurs when the sample is being exposed to oxygen.

Some independent justification for this mechanism was obtained through low-energy electron diffraction (LEED) measurements on thorium single crystals exposed to oxygen. With sufficient exposures a LEED pattern developed that was characteristic of $\mathrm{ThO}_{2}$. For $\mathrm{ThO}_{2}$ to form under these conditions oxygen must dissociate on the thorium surface. The luminescence data presented here support this conclusion.

We are continuing to use electron-induced luminescence as a means to study the oxidation of thorium. We plan to measure the emission spectrum of the thorium Iuminescence under various surface conditions in order to distinguish between luminescence from diatomlc and monatomic oxygen adsorbed on thorium. 


\section{Actinide Spectroscopy}

Responsible Personnel: E. F. Worden, J. G. Conway, * and M. W. Jepson.

Brief Description:

We have compiled for publication a list of the 2034

strongest curium lines emitted by an electrodeless

lamp. The investigation of isotope shifts in the

curium emmission spectrum yeilded a number of new

isotope-shift values in $\mathrm{Cm} \mathrm{I}$ and $\mathrm{Cm} I I$. Spertra have

been taken for determining isotope shifts in the

californium emission spectrum.

Status: The strongest 2034 lines of curium emitted by an electrodeless lamp have been compiled from our 13 420-1ine list for the repion 240 to $1120 \mathrm{~nm}$. The 1ist will be published in Atomic Data and Nuclear Data Tables 18, November (1976). Wavelengths, wavenumbers, and relative intensities are given. Only intensities over 100 on a 0 to 10000 scale are included. Zeeman-effect data, spectrum assignment as neutral or singly ionized lines, isotope shift, and energy-level classifications are given for most of the lines. Isotope shift measurements have been completed for the region 345 to $850 \mathrm{~nm} .^{7}$ Shifts for over 5000 lines have been measured and the data are being catalogued. A number of new isotope shift values in $\mathrm{Cm} I$ and $\mathrm{Cm}$ II have been obtained. Shifts for most important configurations in $\mathrm{Cm}$ II have been derived and are given in Table 3. Except for the ground state, the values are "average" for the configuration with \pm indicating the range.

For isotope shift studies of californium, electrodeless lamps containing three different mixtures of the isotopes ${ }^{249} \mathrm{Cf},{ }^{250} \mathrm{Cf},{ }^{251} \mathrm{Cf}$, and ${ }^{252} \mathrm{Cf}$ were prepared. Exposures for the region $230 \mathrm{~nm}$ to $1000 \mathrm{~nm}$ were taken on the Argonne National Laboratory 9.15-m spectrograph. Over one hundred and thirty 46-cm plates were exposed to cover the range in seven separate exposures. The nuclear spin of ${ }^{251} \mathrm{Cf}$ was determined to be $1 / 2$ by observation of a number of ${ }^{251}$ Cf lines with two components. This is the value predicted by nuclear decay systematics. 8 Isotope shift measurements will require several years at the current level of support.

* Nuclear Chemistry Division, Lawrence Berkeley Laboratory, Berkeley, Calif.

7. General Chemistry Division Quarter1y Report, January through March, 1975, Lawrence Livermore Laboratory, Rept. UCID-15644-75-1 (1975), p. 16.

8. C. M. Lederer, J. M. Hollander and I. Perlman, Table of Isotopes (John Wiley, New York, 1967), p. 443. 
Table 3. Isotope shifts (IS) in Cm II configurations relative to $5 f^{7} 7 s^{2}$ as zero.

Configuration

$5 \mathrm{f}^{7} 7 \mathrm{~s}^{2}$

$5 \mathrm{f}^{8} 7 \mathrm{~s}$

$5 \mathrm{f}^{8} 6 \mathrm{~d}$

$5 \mathrm{f}^{7} 7 \mathrm{~s} 7 \mathrm{p}$

$5 \mathrm{f}^{7} 6 \mathrm{~d} 7 \mathrm{p}$

$5 \mathrm{f}^{7} 6 \mathrm{~d} 7 \mathrm{~s}$

$5 \mathrm{f}^{7} 6 \mathrm{~d}^{2}$

$5 f^{8} 7 p$

${ }^{a}$ IP $=$ Ionization potential

Leve1 energy
range, $\mathrm{cm}^{-1}$$\quad$ IS $\left(\begin{array}{c}246 \sigma-\mathrm{cm}^{-1} \\ \hline\end{array}\right.$

$\quad 0.00$
$2100-35000$
$18000-I P^{a}$
$25000-I P$
$29000-I P$
$4000-35,000$
$14,500-40,000$
$26,000-I P$

0.00

$0.73 \pm 0.1$

$1.19 \pm 0.15$

$0.45 \pm 0.1$

$1.0 \pm 0.1$

$0.5 \pm 0.05$

$0.9 \pm 0.1$

$1.0 \pm 0.1$

$b_{\text {Mean value, } \pm \text { indicates range }}$ 


\section{Accurate Determination of the Internal}

\section{Diameter of a Hollow Sphere}

Responsible Personnel:

Brief Description:
R. W. Crawford and H. E. Crampton ${ }^{*}$

An apparatus was designed and buflt to accurately measure the inside diameter of a hollow sphere. Although the only access was through a very small hole in the wall of the sphere, we were able to achieve a precision of $\pm 1.5 \mu \mathrm{m}$.

Status: Measurements of the outer diameter of a hollow spherical part showed that there was shrinkage after heat treating. It was necessary to see if comparable shrinkage occurred on the inside. Access to the inside was through a very small diameter hole. Changes of the inner diameter of the order of $2.5 \mu \mathrm{m}(0.1 \mathrm{mil})$ had to be detected.

Our approach was to fill the sphere with mercury and weigh it before the heat treatment and then repeat the procedure after heat treatment. The sphere was attached to a vacuum system by an 0-ring, evacuated, and heated to approximately $100^{\circ} \mathrm{C}$ for several hours to remove adsorbed gas. Mercury was then flowed into the sphere while the part was under vacuum. Extreme care was taken to avoid contamination of the mercury with grease or particulates that could plug the hole. When the sphere was filled, an excess of mercury was pooled over the hole and two atmospheres of argon were applied to help force the mercury into the sphere.

After temperature stabilization, the sphere was wiped with a chamois cloth and then weighed on an analytical balance. The balance room was made deliberately cooler than the mercury at flling time to eliminate expansion and loss of the fluid.

Excellent precision was achieved in the measurement. The diameters calculated from the measured mercury weights for one sphere before and after heat treatment differed by $0.002 \mathrm{~cm}$ with a precision of $\pm 1.5 \mu \mathrm{m}$.

\footnotetext{
*Materials Fabrication Division, LLL.
} 
An Infrared Method for Determining

1,3,5-Triazido-2,4,6-trinitrobenzene (TATNB)

in Benzotrisfuroxan (BTF)

Responsible Personnel: R. H. Sanborn

Brief Description:

Small amounts of triazidotrinitrobenzene are suspected to be the cause of an explosion that occurred during the pressing of BTF. We estimated the amount of TATNB in several batches of BTF by measuring the intensity of the $2145 \mathrm{~cm}^{-1}$ band in $\mathrm{CCl}_{4}$ extracts of BTF. . The method is capable of detecting concentrations of about $0.01 \mathrm{mg} / \mathrm{ml}$.

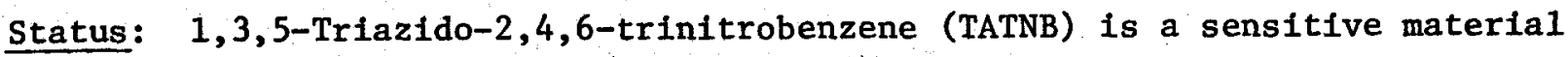
suspected as an impurity in a batch of benzotrisfuroxan (BTF) that exploded during pressing. The quantity of TATNB in samples of several batches of BTF was estimated by an infrared method. The azido group was found to absorb uniquely between 2110 and $2150 \mathrm{~cm}^{-1}$ in $\mathrm{CCl}_{4}$ solutions. The absence of interference allowed us to employ pathlengths of up to $5 \mathrm{~mm}$, providing a very sensitive method. BTF was only sparingly soluble when the TATNB was extracted from the BTF with $\mathrm{CCl}_{4}$.

Figure 3 shows the analysis region of the infrared spectrum of a $\mathrm{CCl}_{4}$ solution of $0.366 \mathrm{mg}$ TATNB $/ \mathrm{cm}^{3}$ with a $5-\mathrm{mm}$ pathlength. The band at $2293 \mathrm{~cm}^{-1}$ is from $\mathrm{CCl}_{4}$ and can be used as an internal standard for normalization. The doublet of TATNB has peaks at 2145 and $2120 \mathrm{~cm}^{-1}$. The broader component at $2145 \mathrm{~cm}^{-1}$ was used for the analysis. The sensitivity of 5-mm pathlengths was found to be about $0.01 \mathrm{mg}$ TATNB $/ \mathrm{cm}^{3}$ on a Beckman IR-8 infrared spectrophotometer.

TATNB was freshly prepared by the reaction of sodium azide with trichlorotrinitrobenzene in ethanol and was purified only by an ethanol wash. A standard solution containing $0.07 \mathrm{~g}$ TATNB in $50 \mathrm{~cm}^{3} \mathrm{CCl}_{4}$ was found to be slightly contaminated with ethanol. A calibration curve of normalized absorbance versus concentration was determined by measuring solutions prepared from dilutions of the standard. It was linear up to $0.55 \mathrm{mg} / \mathrm{cm}^{3}$. Two-gram samples of BTF were extracted with $50 \mathrm{~cm}^{3}$ portions of $\mathrm{CCl}_{4}$. The percentages of TATNB found in the five batches of BTF are given in Table 4. The values must be considered as upper limit estimates because of 


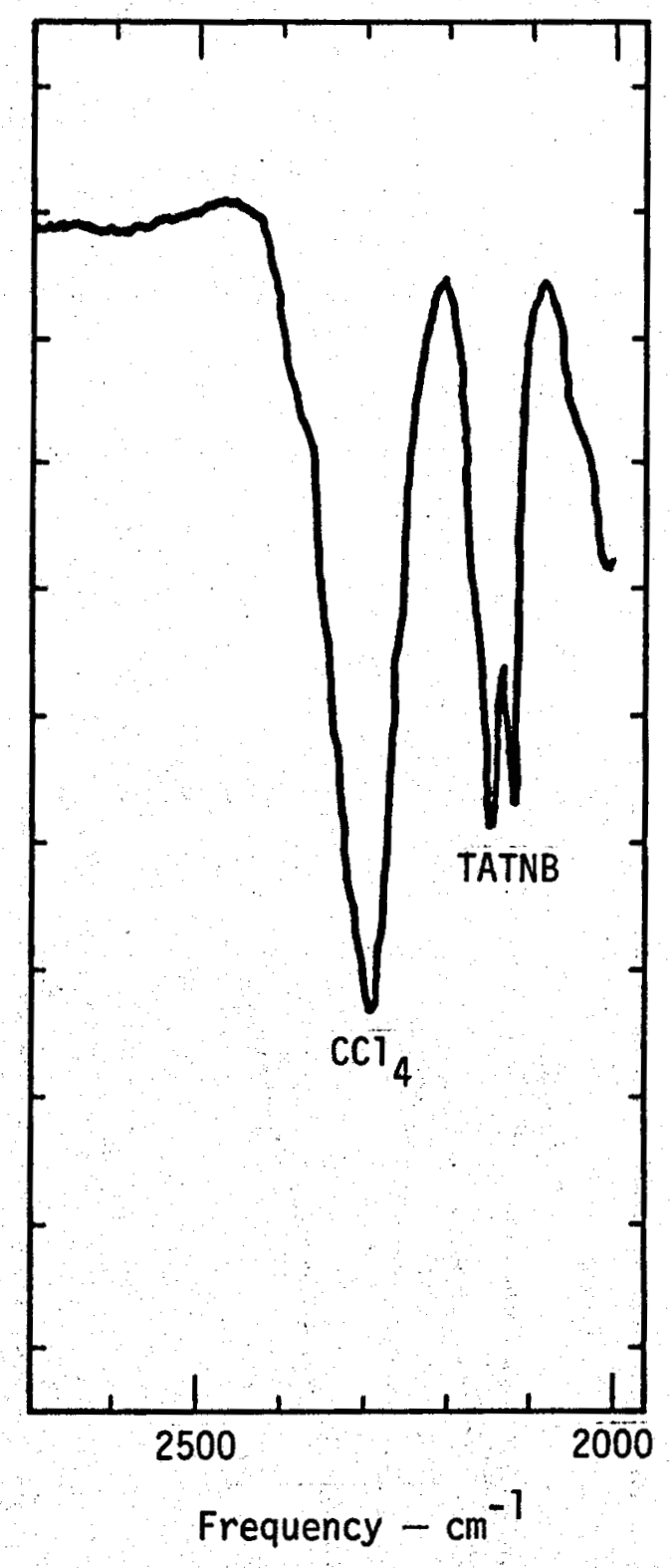

Fig. 3. Infrared bands of TATNB and the solvent $\mathrm{CCl}_{4}$ (5-mm pathlength ce11). 
the ethanol found in the standard solution and doubts about the purity of the TATNB used to prepare the standard. A variable, amount of an additional unknown impurity that absorbed at $1695 \mathrm{~cm}^{-1}$ was found in all of the extracts except the recrystallized lot B-053. Benzotrisfuroxan from batch B-053 was not used for the pressing. The results show that TATNB is effectively removed from BTF by recrystallization.

Table 4. Determination of TATNB in batches of BTF.

\begin{tabular}{ll}
\hline Batch No. & TATNB, \% \\
\hline B-007 & 0.45 \\
B-053 & 4.9 \\
B-053 (recrystallized) & 0.0 \\
B-105 & 2.29 \\
B-135 & 0.021 \\
\hline
\end{tabular}




\section{Determination of Hydroxyl in Polyols}

Responsible Personnel: W. Selig

Brief Description:

Several modifications of the acetylation method for the determination of hydroxyl compounds were evaluated for application to polyols.

Status: We previously reported a semimicro method for the determination of hydroxyl and amino compounds. ${ }^{9}$ This method was a modified version of the pyromellitic dianhydride (PMDA) method developed by Siggia. ${ }^{10,11}$ A recent round-robin meeting of ERDA laboratories on the determination of hydroxyl in polyols revealed that LLL was the only laboratory using the PMDA method. ${ }^{12}$ our. results were slightly lower than those reported by the other three laboratories who use acetylation methods. These polyols contained other 1inkages. Therefore we investigated acetylation methods for the analysis of polyols. We first examined the perchloric acid/acetic anhydride method reported by Fritz and Schenk. ${ }^{13}$ This method has several advantages over the standard acetir anhydride methods. The reagent is stable for at least 2 weeks (vs 1 day in the standard method), and the reaction requires only. $5 \mathrm{~min}$ at ambient temperature (vs a reflux for $45 \mathrm{~min}$ or more). This method worked well with our model compound 1-octadecanol. However, the very high results obtained for the polyols showed that the ether linkages were attacked by the reagent. Thus this method cannot be used for compounds containing ether linkages. Next, we slightly modified the procedure of $0 \mathrm{gg}$ et al., ${ }^{14}$ given by Siggia. ${ }^{15}$ Samples ( 3 to $4 \mathrm{meq}$ ) were reacted with $5.00 \mathrm{~cm}^{3}$ of freshly prepared reagent (acetic anhydride/pyridine). The reaction mixture was heated for $45 \mathrm{~min}$ on a hotplate at $90^{\circ} \mathrm{C}$ using an air-condenser. The colorimetric endpoint corresponded to a $\mathrm{pH}$ of 11.35 to 11.5 . Otherwise the method was the same as that outlined by Siggia. The average results for our model compound (1) octadecanol) were $6.29 \% \mathrm{OH}$ (vs a theoretical value of $6.29 \%$ ).

i. W. Selig, Microchem. J., 21, 92 (1976).

1i). S. Siggia and J. G. Hanna, Anal. Chem. 37, 600 (1965).

I1. S. Siggia, J. G. Hanna, and R. Culmo, Ana1. Chem. 33, 900 (1961).

i. F. N. Larsen, The Bendix Corporation, Kansas City, Mo. Internal memorandum of August 19, 1976.

3. J. S. Fritz and G. H. Schenk, Anal. Chem. 31, 1808 (1959).

14. C. L. Ogg, W. L. Porter, and C. 0. Willis, Ind. Eng. Chem., Ana1. Ed., 17, 394 (1945).

15. S. Siggia, Quantitative Organic Analysis Via Functional Groups, 3rd ed., (Wiley, New Yurk, 1976) p. 12. 
In a second modification we heated for only $30 \mathrm{~min}$ at $90^{\circ} \mathrm{C}$, used $5 \mathrm{~cm}^{3}$ of water to hydrolyze the excess of acetic anhydride (vs $10 \mathrm{~cm}^{3}$ ), and substituted pyridine for $n$-butanol. The results for 1 -octadeconal were slightly lower (mean of $6.23 \% \mathrm{OH}$ ), but st111 acceptable.

We have also attempted to use the modified acetylation method for the determination of the amine content in 1,3-diamino-2,4,6-trinitrobenzene (DATB). Using the same conditions that we used for 1 -octadecanol, only $275 \%$ of the . theoretical amount of $\mathrm{NH}_{2}$ was recovered. Further work is in progress. 


\section{Analysis of Explosive Composites}

Responsible Personnel: G. L. Crossman and W. Selig

Brief Description: A method was developed for the analysis of a composite explosive containing pentaetythritol tetranitrate (PETN), ammonium nitrate (AN), and water.

Status: An explosive composite containing PETN, AN, and water was analyzed. Preliminary experiments showed that attempts to remove water by vacuum drying also removed some of the AN (MP $169.6^{\circ} \mathrm{C}$ ). The composite was therefore analyzed as recelved. The PETN was recovered gravimetrically after hot-water extraction on a medium-porosity filter crucible. The aqueous extract, which contained the AN, was recovered quantitatively in a volumetric flask.

Aliquots of the AN solution were analyzed for ammonium ion by the formo $1^{16,17}$ titration, which is based on the reaction

$$
6 \mathrm{HCHO}+4 \mathrm{NH}_{4}^{+} \longrightarrow\left(\mathrm{CH}_{2}\right)_{6} \mathrm{~N}_{4}+4 \mathrm{H}^{+}+6 \mathrm{H}_{2} \mathrm{O} .
$$

The acid formed when formaldehyde reacts with ammonium ion was titrated with standard base using a Sargent recording titrator. The base was standardized vs reagent-grade AN. The titration was monitored by a glass/calomel electrode pair.

Some representative results are shown in Table 5.

Table 5. Analysis of explosive composite B-249.

\begin{tabular}{llll}
\hline & PETN, \% & AN, \% & Water, \% \\
\hline Sample A & 37.04 & 25.58 & \\
& & 25.58 & \\
Sample B & 37.03 & 25.61 & \\
& & 25.61 & \\
Mean & 37.04 & 25.60 & $37.36^{\mathrm{a}}$ \\
\hline
\end{tabular}

a Calculated by difference

16. F. J. Welcher, Organic Analytical Reagents (Van Nostrand, New York, 1946), Vo1. 1, p. 376.

17. C. L. Wilson and D. W. Wilson, Eds., Comprehensive Analytical Chemistry, Vo1. IC, (Van Nostrand, Princeton, NJ, 1962), p. 204. 
The duplicate results for AN are replicates of the same water extract and show the precision obtainable by this method.

We have also investigated an alternative, and possibly simpler approach to this analysis: AN can be titrated directly as a base with perchloric acid/glacial acetic acid titrant in a glacial acetic acid medium. PETN does not interfere and is sufficiently soluble in acetic acid so that all the components of this composite will dissolve. The PETN is determined gravimetrically by hot-water extraction of the other components on a separate sample. 


\section{Study of a New Potassium Ion-Selective Electrode}

\section{Responsible Personnel: W. Selig}

Brief Description:

An Orion model 93-19 potassium ion-selective electrode was used in the titration of potassium with sodium tetraphenylboron.

Status: Lal and Christian ${ }^{18}$ reported that the Orion model 92-19 potassium ion-selective electrode, was only "moderately useful" for potentiometric titrations of potassium with sodium tetraphenylboron because the endpoint breaks were only 10 to $15 \mathrm{mV}$.

Recently a new modẹl potassium electrode (No. 93-19) became available from Orion Research Inc., and it is simpler to use than the previous one. We have attempted to use the new electrode for the potentiometric titration of potassium with sodium tetraphenylboron. Our PDP-8/I minicomputer system 19 was used to generate titration curves. A representative titration curve is shown in Fig. 4. This also includes the Gran plot of that portion of the curve where the titrant was in excess, as well as the Iinearized Gran plot described previousiy. 19 Attempts were made to calculate endpoints by the second derivative method according to the method of Savitsky and Golay. 20 The data were convoluted with a third-order second derivative with 25 points. Twenty-five points, however, were insufficient to locate the endpoint unambiguously. Using Gran plots, on the other hand, one can estimate potassium successfully.

We attempted to increase the steepness of the titration curve and the magnitude of the endpoint breaks by applying small polarization currents to the electrodes. Currents from -0.7 to $+2.0 \mu \mathrm{A}$ were investigated. Negative polarization currents had no effect. The best results were obtained with currents from +1.25 to $+1.75 \mu \mathrm{A}$. This is shown in Fig. 5. However, with increasing polarization currents, the curves tend to be nolsier; consequently, the Gran plots are less linear than in the absence of polarization currents.

Further experiments are planned using more than 25 points in the Savitsky-Golay convolute.

18. S. Lal and G. D. Christian, Anal. Letters, 3, 11 (1970).

19. J. W. Frazer, A. M. Kray, W. Selig, and R. Lim, Anal. Chem., 47, 869 (1975). 20. A. Savitsky and M. J. E. Golay, Anal. Chem., 36, 1627 (1964). 


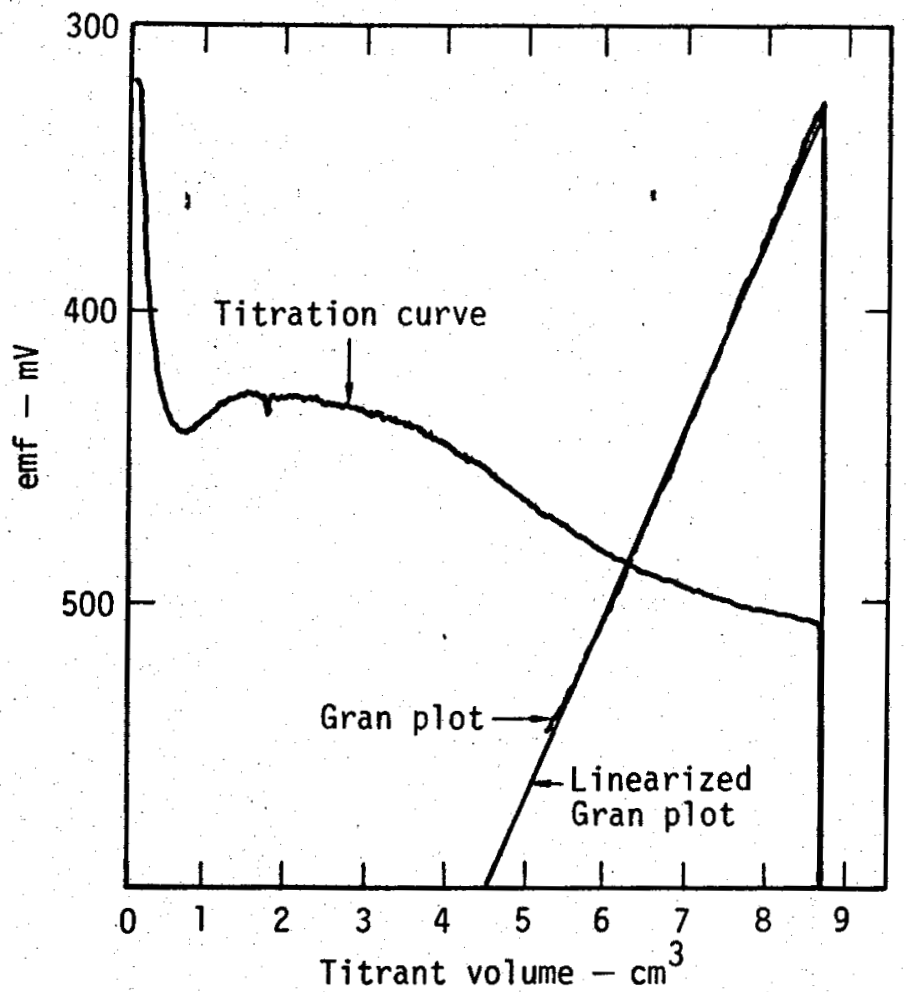

Fig. 4. Titration of $0.125 \mathrm{mmol}$ of potassium with $0.05 \mathrm{~N}$ sodium tetraphenylborate. No applied polarization current.

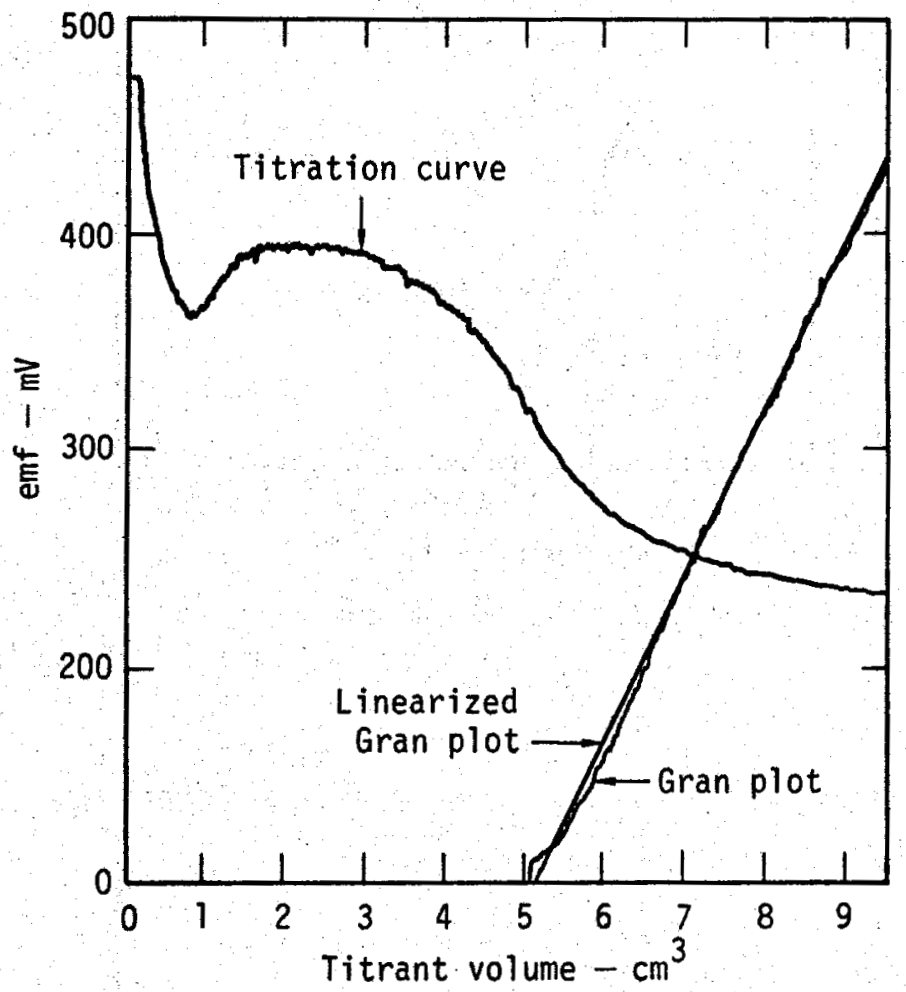

Fig. 5. Titration of $0.125 \mathrm{mmol}$ of potassium with $\sim 0.05 \mathrm{~N}$ sodium tetraphenylborate using an applied polarization current of $1.5 \mu \mathrm{A}$. 
Lower Limits of the Potentiometric Titration of Perchlorate Using a Perchlorate Ion-Selective Electrode

Responsible Personne1: W. Selig

Brief Description: Tetraphenylarsonium chloride, tetraphenylphosphonium chloride, and tetra-n-pentylammonium bromide were evaluated as titrants for the potentiometric determination of perchlorate. The lower limit of this titration at ambient temperature was explored.

Status: The potentiometric titration of perchlorate with tetraphenylarsonium chloride and a perchlorate ISE was first reported by Baczuk and DuBois. 21 Smith and Manahan ${ }^{22}$ improved the sensitivity of this titration by operating at $2^{\circ} \mathrm{C}$.

We have evaluated the titrants tetraphenylarsonium chloride, tetraphenylphosphonium chloride, and tetra-n-pentylammonium bromide for the potentiometric titration of perchlorate. Emf's were monitored with a perchlorate ionselective indicator electrode and a double-junction reference electrode. The tetraphenylonium salts were equivalent, yielding the same precision and magnitude of potentiometric breaks. Considerably smaller breaks were obtained with tetra-n-pentylammonium bromide which, therefore, is not recommended as titrant.

The lower limit for the potentiometric titration of perchlorate at ambient temperature was extended to $20.09 \mathrm{mmol}$ per $50 \mathrm{~cm}^{3}\left(1.7 \times 10^{-3} \mathrm{M}\right)$ from the previous $0.25 \mathrm{mmol}$ per $50 \mathrm{~cm}^{3}$. If Gran plots are used the limit can be further extended to $0.01 \mathrm{mmol}$ per $50 \mathrm{~cm}^{3}\left(2.1 \times 10^{-4} \mathrm{M}\right)$. The integrated automated titration system controlled by a PDP-8/1 minicomputer ${ }^{23}$ was used to generate titration curves and evaluate the experimental results. Detalls have been reported. 24

21. R. J. Baczuk and R. J. DuBois, Anal. Chem., 40, 685 (1968).

22. M. J. Smith and S. E. Manahan, Anal. Chim. Acta 48, 315 (1969).

23. J. W. Frazer, A. M. Kray, W. Selig, and R. Lim, Anal. Chem. 47, 869 (1975).

24. W. Selig, Lower Limits of the Potentiometric Titration of Perchlorate Using a Perchlorate Ion-Selective Electrode, Lawrence Livermore Laboratory, Rept. UCRL-78326 (1976). 
Characterization of a Pulse-Pumped Dye Laser

Responsible Personnel: J, H. Richardson, L. L. Steinmetz, ${ }^{*}$ and B. W. Wallin. ${ }^{\dagger}$

Brief Description: The broad-band output of a dye laser pumped by a cavity-dumped argon-ion laser has been characterized as a function of the pump pulse parameters. 25,26 Spatial hole burning is proposed as the mechanism responsible for wavelength sweeping.

Status: A rapidly pulsing tunable dye laser can be made by using a cavitydumped ion laser to pump a conventional dye laser. Such a light source would be very useful for time-correlated fluorescence spectroscopy. This technique is useful for the selective analysis of mixtures. Initial experiments Indicated that both the tuning range and gain profile as well as the spectraltemporal evolution of dye lasing were a function of the pump pulse parameters (width, amplitude, and shape). We also observed that lasing commenced at the shortest wavelengths, sweeping in time to longer wavelengths. This sweep tends to increase as the pulse-width increases.

The present work extends the observation of wavelength sweeping into a time domain and pump amplitude not previously reported. This has allowed us to discount several possible explanations for sweeping (inhomogeneous line broadening, vibrational relaxations). Additionally, a thermal explanation is unlikely since there was no change in the wavelength sweep when the dye was cooled to $-13^{\circ} \mathrm{C}$. Finally, no wavelength sweep was observed when the dye laser was mode locked, although the average pump power increased and the dye-laser intercavity average power remained essentially constant. This also argues against a thermal effect.

Spatial hole burning has been reported for both solid state lasers and dye lasers. This mechanism would explain our observations of wavelength sweep. Spatial burn-out of the high gain modes would force mode shifts to longer wavelengths because of the skewed gain curve. To check for possible

\footnotetext{
* Electronics Engineering Department, LLL.

+ Research Engineering Division, LLL.
}

25. J. H. Richardson, L. L. Steinmetz and B. W. Wallin, Dynamics of a Variably Pulse-Pumped Dye Laser, Lawrence Livermore Laboratory, Rept. UCRL-78398 Rev. 1 (Preprint), 1976.

26. General Chemistry Division Quarterly Report, April through June, 1976, Lawrence Livermore Laboratory, Rept. UCID-15644-76-2 (1976) p . 14. 
spatial hole burning, we placed a lithium tantalate phase modulator Inside the dye laser cavity and drove it at several hundred volts and $40 \mathrm{MHz}$. This effectively modulates the cavity length by one wavelength at a $40 \mathrm{MHz}$ rate. The extent of the wavelength sweep does decrease significantly, but it is not solely ascribable to a diminished hole burning. The cavity loss is also increased and losses tend to reduce the sweep. When the dye laser was continuous wave (CW) mode locked, no wavelength sweep occurred. While it is not conclusive that spatial hole burning is the mechanism responsible for wavelength sweeping, it does agree with experimental observations. 


\section{Laser-Induced Molecular Fluorescence}

Responsible Personnel: M. E. Ando ${ }^{*}$ and J. H. Richardson

Brief Description: Our work in laser-induced molecular fluorescence is

being extended to include a survey of aromatic

molecules. Initial results Indicate sensitivities of

better than one part-per-trillion (ppt), a considerable

improvement over previous minimum detectability limits.

Status: The absorption spectra of a number of polynuclear aromatic hydrocarbons were measured in appropriate solvents. Molecules to be studied were chosen on the basis of their absorption (absorptivity > 10,000), fluorescence spectra separation from pump $>50 \mathrm{~nm}$ ), reported lifetimes ( $>10 \mathrm{nsec}$ ), and possible analytical relevance to LLL programs.

The instrumentation and experimental techniques were essentially the same as previously described. ${ }^{27}$ The laser fundamental at $546 \mathrm{~nm}$ (C495 dye) was frequency doubled to match the more intense UV absorption bands of the polynuclear aromatic hydrocarbons; and UV-grade optics were incorporated into the sample chamber.

Figure 6 shows the dependence of the fluorescence intensity of naphthalene on its concentration in water; this linear working curve was extended to $1 \times 10^{-6} M$. All data were taken with a Jobin-Yvon-H20 monochromator at $335 \mathrm{~nm}$ ( $8 \mathrm{~nm}$ FWHM). The minimum detectability, $1 \times 10^{-11} \mathrm{M}$, corresponds to $1.3 \mathrm{ppt}$. This sensitivity is more than an order of magnitude greater than a recently reported limit of detection by a fluorescent method. 28

Figure 7 shows the concentration dependence of the fluorescence intensity of pyrene in water. The linear working curve was extended to $1 \times 10^{-7} \mathrm{M}$; pyrene was insoluble at higher concentrations. All data were taken with a Jobin-Yvon-H20 monochromator at $395 \mathrm{~nm}(8 \mathrm{~nm}$ FWHM). The minimum detectab1lity, $2.5 \times 10^{-12} \mathrm{M}$, corresponds to $0.20 \mathrm{ppt}$. This sensitivity is more than two orders of magnitude greater than the recently reported limit of detection. 27

* Summer employee, University of California, Santa Barbara, Calif.

27. J. H. Richardson, B. W. Wallin, D. C. Johnson and L. W. Hrubesh, Anal. Chim. Acta 86, 263 (1976).

28. F.P. Schwarz and S. P. Wasik, Anal. Chem. 48, 524 (1976). 


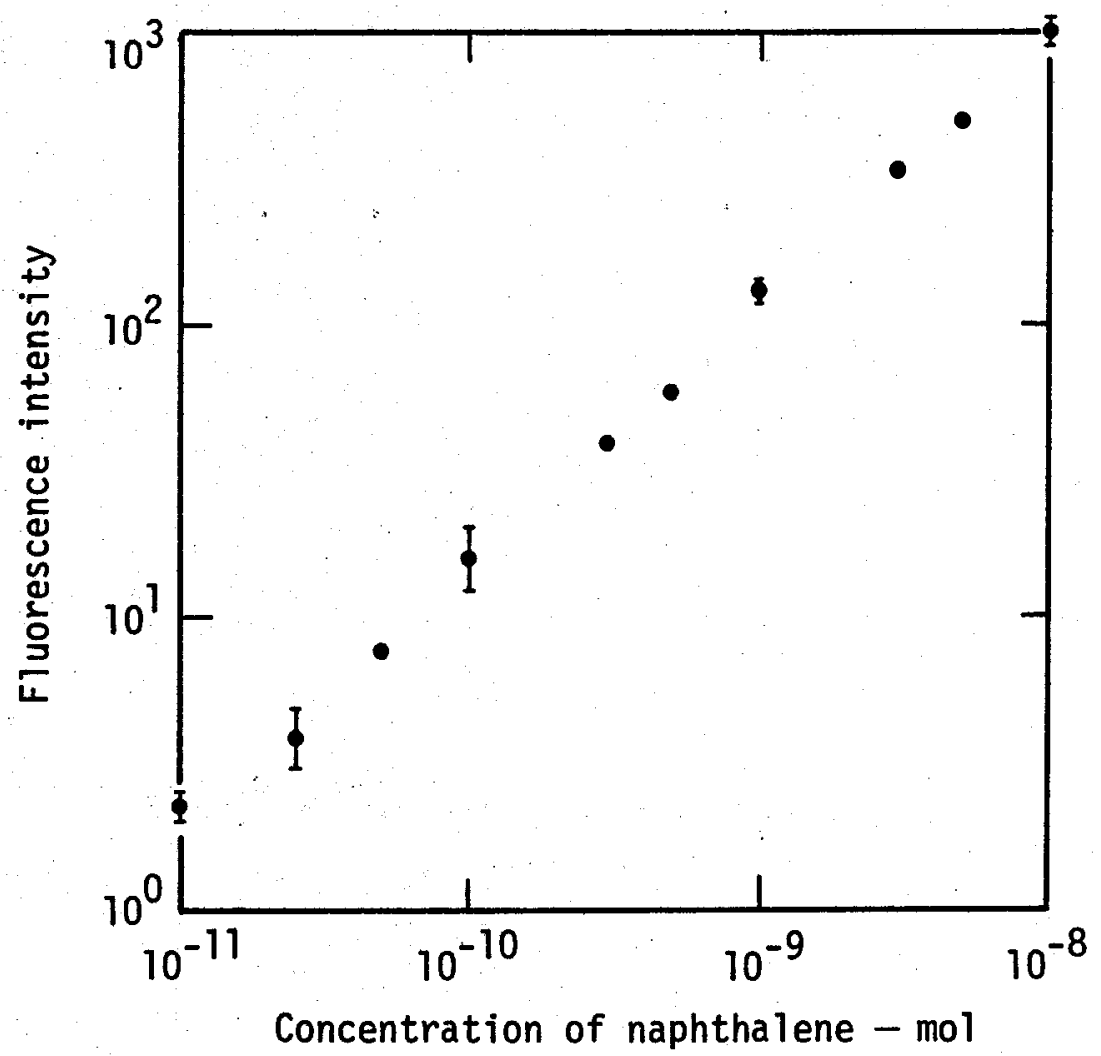

Fig. 6. Laser-induced fluorescence of napthalene.

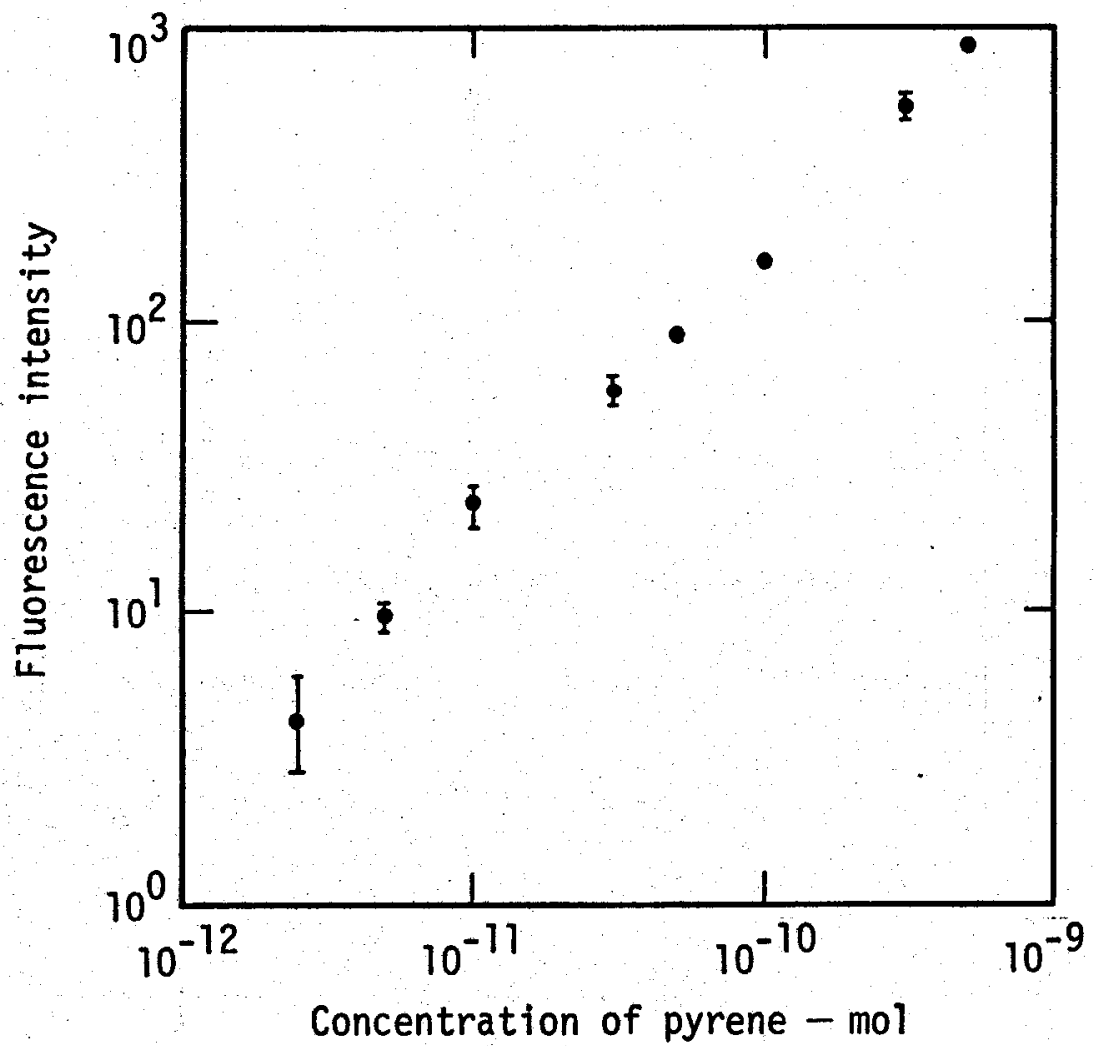

Fig. 7. Laser-induced fluorescence of pyrene. 
An expected improvement in sensitivity using only filters could not be realized due to the relatively large solvent background in the UV. A longer fluorescent lifetime coupled with a longer fluorescent wavelength enabled the greater sensitivity to be achieved for pyrene.

Not all aromatics are highly fluorescent. For example, we found that DOP (dioctyl phthalate) and its precursor, phthalic acid did not fluoresce. There are many fluorescent labels, however, which could facilitate sensitive determination of non-fluorescent compounds. One such label, fluorescamine, is specific for primary amines. It is currently being investigated using o-nitro aniline as the non-fluorescent substrate. 


\section{The Effect of Stress on the Fluorescence of Kevlar Fiber}

Responsible Personnel: J. H. Richardson, G. R. Haugen, L. S. Penn, * J. H. Feikert ${ }^{\dagger}$ and R. J. Sherry. ${ }^{\dagger}$

Brief Description: We are attempting to correlate the fluorescence spectrum of Kevlar ${ }^{* *}$ with applied stress. We find that fluorescence intensity is correlated with stress.

Status: Preliminary studies have been completed, documented, and further work has been proposed. 29 The experimental procedures and initial results were previously described. ${ }^{* *}$ Table 6 summarizes the data that were obtained.

The purpose of this study was to determine whether laser-induced fluorescence might reveal any of the molecular details assoclated with applying a uniaxial stress to Kevlar fibers. It is concelvable that laser fluorescence would prove useful as a non-destructive diagnostic monitor of changes in Kevlar-epoxy composite parts. Hopefully, a change in the fluorescence spectrum could be correlated to a use-related varlable such as stress-level or environmental conditions. Such correlations would eventually enable more accurate predictions of lifetimes of composite parts.

The data show a correlation between fluorescence intensity and stress. Experiments with single filaments would be easier to interpret. Tension undoubtedly affects the inter-and intra-molecular configurations; it would be interesting to probe this changing molecular environment with various quenchers. The lifetime of the fluorescence would also be a function of stress and could be investigated accordingly. Theoretical studies of the fluorescence spectrum would provide Insight into the effect of nearest-neighbor interactions.

\footnotetext{
* Organic Materials Division, LLL.

** See page 12 of Ref. 26

$\dagger$ Research Engineering Division, LLL.

t+ A polyamide fiber made by Dupont.
}

29. J. H. Richardson, G. R. Haugen, L. S. Penn, J. H. Feikert and R. J. Sherry, The Effect of Stress on the Fluorescence of Keviar Fiber, UCID- (1976), p. 12 . 
Table 6. Ratio of fluorescence intensity ( $I_{F}$ ) to scatter intensity (IS) vs stress. Nos. 7-9 were epoxy coated. Parentheses indicate breaking stress in $\mathrm{kg} / \mathrm{cm}^{2}$.

\begin{tabular}{|c|c|c|c|c|c|c|c|c|c|c|}
\hline $\begin{array}{l}\text { Stress } \\
\mathrm{kg} / \mathrm{cm}^{2}\end{array}$ & $\begin{array}{r}\text { Sample } \\
\text { No. }\end{array}$ & 1 & 2 & 3 & 4 & 5 & 6 & 7 & 8 & 9 \\
\hline 0.00 & & 1.00 & 1.00 & & 1.00 & 1.00 & 1.00 & & 1.00 & \\
\hline 0.05 & & 1.06 & & 1.00 & 1.12 & 1.09 & 0.99 & 1.00 & .99 & 1.00 \\
\hline 0.10 & & 1.18 & 1.10 & 1.04 & 1.23 & 0.85 & 0.92 & 1.02 & 1.07 & 1.19 \\
\hline 0.15 & & & & & 1.63 & 0.99 & 0.89 & 1.02 & 1.08 & 1.17 \\
\hline 0.20 & & 1.45 & 1.15 & 1.09 & 1.84 & 0.94 & 0.88 & 1.06 & 1.06 & 1.21 \\
\hline 0.25 & & & & 1.03 & 2.18 & 0.97 & 0.92 & 1.07 & 1.08 & 1.21 \\
\hline 0.28 & & & & & $\begin{array}{c}2.38 \\
(0.28)\end{array}$ & $(0.28)$ & $(0.28)$ & & & $(0.29)$ \\
\hline 0.30 & & $\begin{array}{c}1.63 \\
(0.32)\end{array}$ & $\begin{array}{c}1.15 \\
(0.35)\end{array}$ & $\begin{array}{c}1.54 \\
(0.32)\end{array}$ & & & & $\begin{array}{l}1.10 \\
(0.35)\end{array}$ & $\begin{array}{c}1.07 \\
(0.30)\end{array}$ & \\
\hline
\end{tabular}

Finally, the dependence of fluorescence parameters might also be studied as a function of temperature; such results might have some bearing on the validity of accelerated aging studies.

The above-mentioned experiments could help elucidate the mechanism of fracture. While not directly of predictive value in determining stressrupture lifetimes, the fluroescence spectroscopy could help establish a model that would at least partly reflect the molecular basis for failure. Such a model is necessary if we are to predict lifetimes accurately. 
New Method for the Determination of Luminescence

Lifetimes by Using the Beat Noise of a CW Laser as a

Multifrequency Modulated Source

Responsible Personnel: G. M. Hieftje* and G. R. Haugen

Brief Description: Excitation of a fluorophore by rapidly varying

fluctuations in a free-running argon-ion laser

produces variations in measured fluorescence,

whose power spectrum has been shown to yield informa-

tion on luminescence lifetimes.

Status: The mode noise in a free-running argon-ion laser can be used to produce variations in the excited-state population of a fluorophore.

Although the mode noise contains extremely high-frequency fluctuations, the excited-state population cannot follow them because of its finite lifetime. A comparison of the power spectra of the mode noise and the luminescence then enables the lifetime of the luminescence to be calculated. In effect, the luminescence process acts like a low-pass exponential filter, whose bandpass is dependent upon the lifetime.

To illustrate the feasibility of the new technique; the fluorescence lifetimes of Rhodamine $B$ and Rose Bengal were determined. In these measurements, an argon-ion laser was optically attenuated and directed alternately into a quartz cuvette containing the fluorophore of interest and into a matched cell containing a scattering suspension. The resulting scattered or fluoresced radlation was detected at $90 \mathrm{deg}$ by a crossed-field photomultiplier tube. The desired mode nolse spectrum was displayed on a spectrum analyzer.

To obtain 1ffetime information from the fluorophore spectrum, it is necessary to correct for instrument response. Since the lifetime information is already displayed in the frequency domain, correction required only a simple division by the power spectrum of the scattered radiation. The resulting envelope of the beam frequency peaks is Lorentzian in shape, which is equivalent to an exponential shape in the time-domain. The envelope has a bandwidth at half-maximum equal to the reciprocal of the excited-state lifetime. This is shown in Fig. 8 which shows the experimental data for two fluorophores and curves calculated for various lifetimes.

* Department of Chemistry, Indiana University, Bloomington, Indiana. 


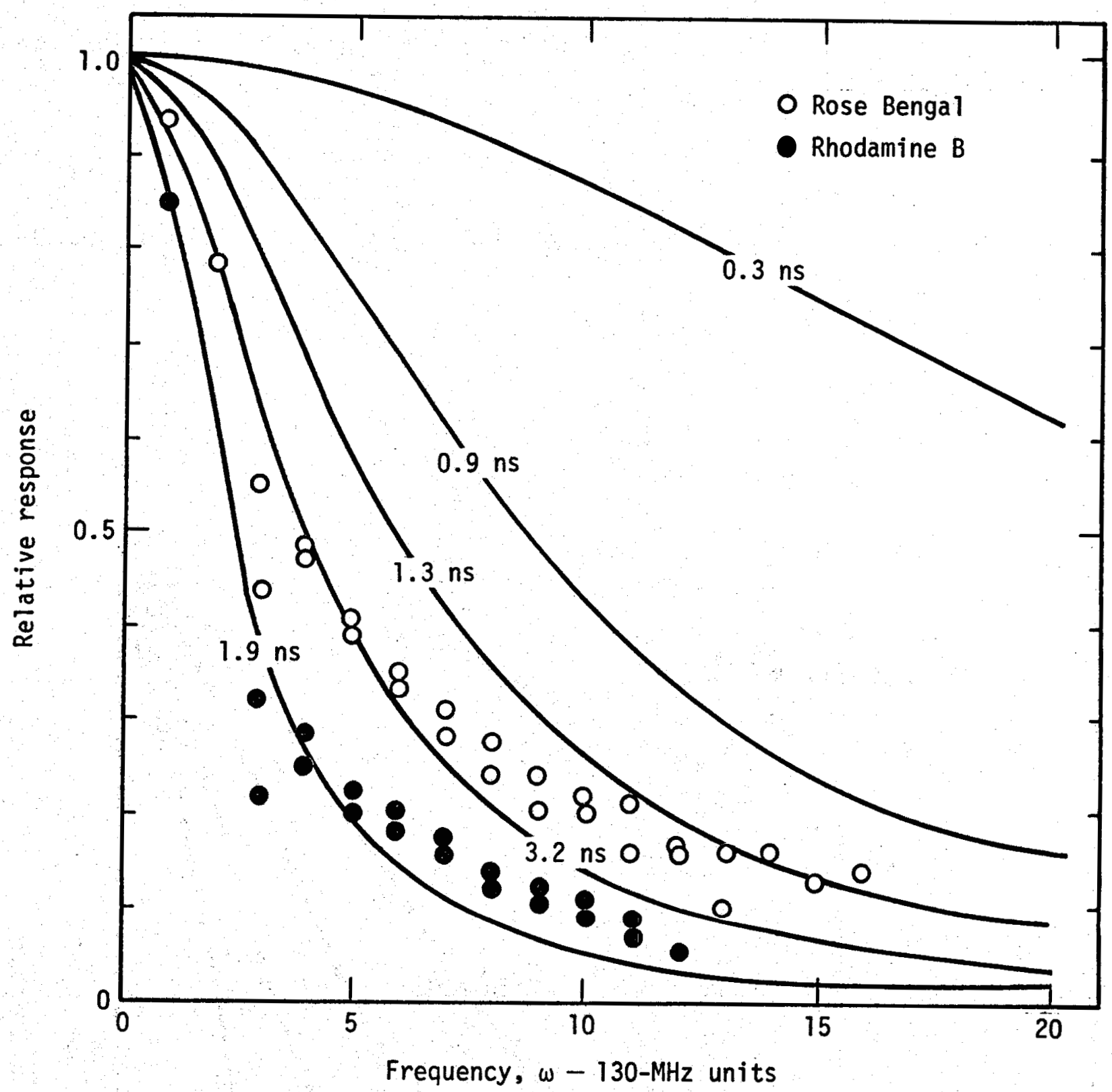

Fig. 8. Frequency response curves for Rose Bengal and Rhodamine B, and curves calculated for various values of lumineşcence lifetime $T$. Relative response calculated from the expression $1 /\left(1+\omega^{2} T^{2}\right)$ 
In the immediate future, we intend to extend the applicability of this new tool by frequency-doubling the argon-ion laser radiation. This modification would not only enable many more fluorophores to be probed, but would also increase the nolse amplitude in the exciting radiation as well, thereby simplifying the necessary noise spectral measurements. We also plan to use laser noise spectra to characterize laser output quality and operation, to measure response time and performance of fast photodetectors, and to measure quantum yields independent of the spectral response of the system. 


\section{DEVELOPMENT OF ANALYTICAL METHODS FOR THE ENERGY PROGRAM}

\section{Geothermal Brine and Solids Characterization}

Responsible Personnel: J. H. Hill, C. J. Morris and C. H. Otto

Brief Description: We are providing technical and analytical support for the Geothermal Total Flow and Industrial Support Programs. This work involves brine characterization, brine modification, scale control, suspended solids characterization and control, and effluent characterization. The analytical support involves the sampling and analysis required to provide input for these experiments.

Status: During the past quarter, 82 samples were taken from the LLL Total Flow Field Test Unit and the San Diego Gas and Electric Company's Geothermal Loop Experimental Facility (GLEF). These samples consisted of 51 brine samples, 6 steam samples, 15 suspended solids samples, and 10 miscellaneous samples of acid, gases, and scale. Each of these samples was analyzed for 2 to 20 constituents. Analysis of 36 samples previously collected in June, 1976 was completed. In addition, approximately 20 samples of scale and sludge solids collected at various times by the project engineers were analyzed by $x$-ray fluorescence, emission spectrography, and wet chemistry.

Reports on brine chemistry and its characterization, and the sampling and characterization of suspended solids have been prepared for incorporation into the geothermal program status report for. FY1976. Some of the data from the first of these reports are shown in Table 7. The effects of flow rate and the effect of position of the sample probe in the pipe on the composition of brine samples were described for samples taken from the Magmamax No. 1 wellhead. Changes in brine composition were reported for four periods of intermittent production during the interval from June 29 to August 10, 1976. The relation of the $\mathrm{CO}_{2}$ and $\mathrm{HCO}_{3}$ - concentration in the brine to acid consumption was discussed. (In this case, the acid was used to lower the $\mathrm{pH}$ and reduce scale formation.) In addition, the composition of the non-condensable gases from the stack on the GLEF was monitored and reported. 
Table 7. Composition of geothermal brine samples from Magmamax wells.

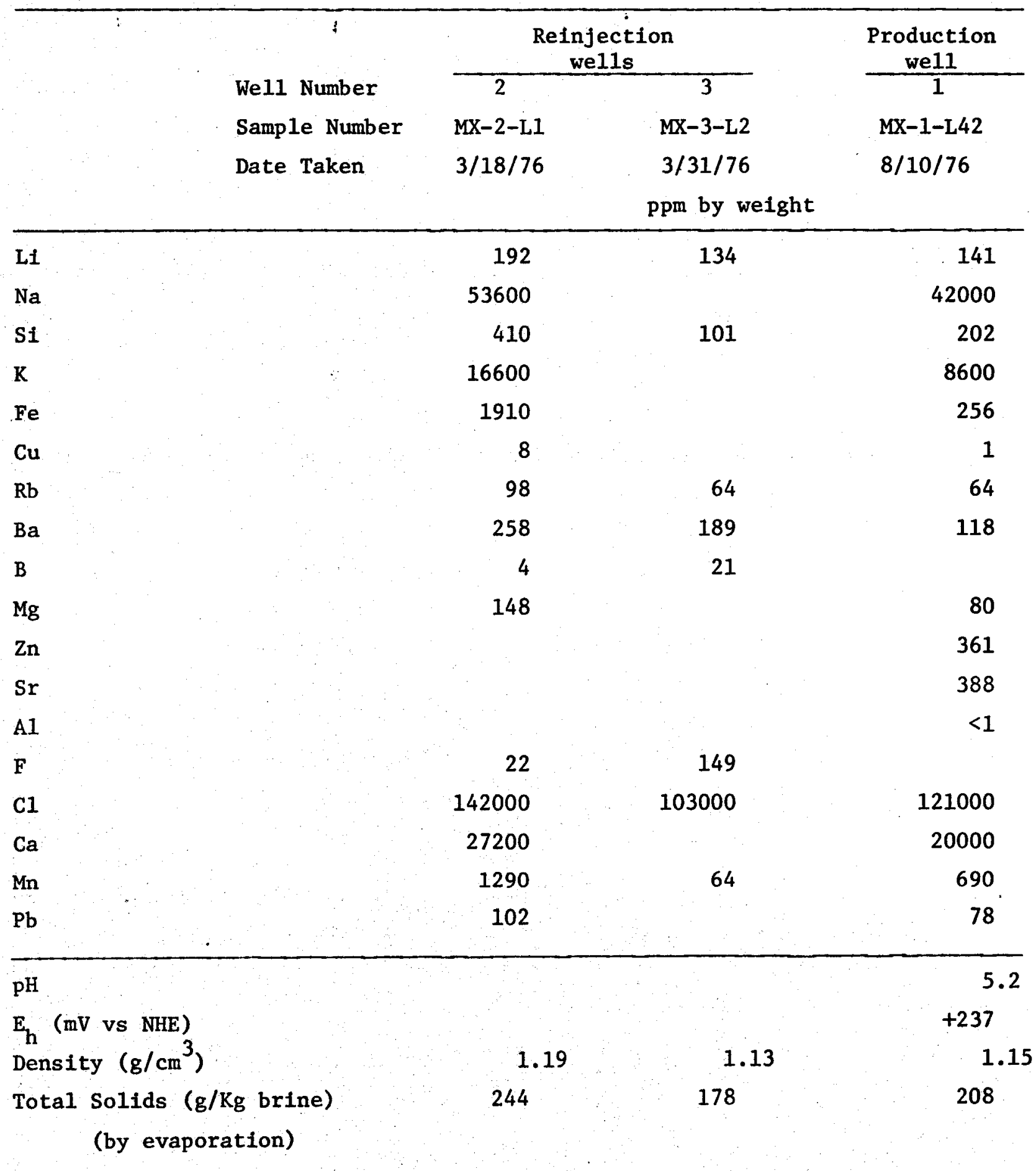


We also obtained data on chemical and mineralogical composition together with particle-size distributions for suspended solids in brine from the three Magmamax wells. The concentration of suspended solids in brine effluent from the GLEF was reported for samples taken out of the reinjection 1ine near the Magmamax No. 3 wellhead. For a $10 \mathrm{MW}$ power plant using $360000 \mathrm{~kg} / \mathrm{h}$ of brine, approximately $4140 \mathrm{~kg} /$ day of solids would be produced from Magmamax No. 1 brine. These sollds will probably cause problems in the reinjection of the brine. Therefore, additional work will be done to devise methods to prevent the formation of these suspended solids or provide for their removal prior to reinjection. 


\section{Continuous Water Monitor for Oil-Shale}

\section{Retort Effluent}

Responsible Personnel: R. L. Morrison

Brief Description: : A pressure sensitive device is used to measure the rise in pressure across a membrane caused by the permeation of water through the membrane. ${ }^{*}$ This rise in pressure can be related to the amount of water in the gas stream passing over the membrane. An instrument based on this device was built to monitor oil-shale retort effluent.

Status: A continuous water monitor for use in the analysis of oil-shale retort effluent has been developed. A schematic diagram of the instrument is shown in Fig. 9. Gas from the retort enters through a heated line, and passes through a trap into a three-way electric.valve. The electric valve is timed to switch the stream every $2.5 \mathrm{~min}$. First the stream goes through the drier, then through an open tube, through the detector cell, and out to the atmosphere. The pressure sensor is a 0 - to $10-\mathrm{mm}$ Barocel with associated power supply. An ordinary laboratory vacuum pump with a capacity of approximately $28 \mathrm{l} / \mathrm{min}$ (1 CFM) (with a Nupro 4BK valve between the pump and the detector cell) provides an adequate vacuum system.

Figure 10 shows a diagram of the detector cell. It is fabricated from stainless steel and consists of an inlet-outlet chamber and a vacuum chamber. The gas to be monitored enters the cell, passes across the surface of the membrane, and vents to the atmosphere. The pressure in the vacuum chamber of the cell is continuously monitored by the Barocel pressure sensor and is recorded on a laboratory recorder.

The membrane used for this application is $0.0025-\mathrm{cm}$ (1-mil) thick dimethyl silicone rubber obtained from the Medical Products Division of General Electric. The membrane is supported by a fine-mesh stainless steel screen and its surface area is approximately $4.5 \mathrm{~cm}^{2}$. The base pressure of the vacuum chamber while dried gas passes over a membrane of this surface area should be approximately 13 to $53 \mathrm{~Pa}$. If the pressure is higher, there is either a leak in the cell or pin holes in the membrane. There is a

\footnotetext{
* See page 2 of Ref. 5 .
} 


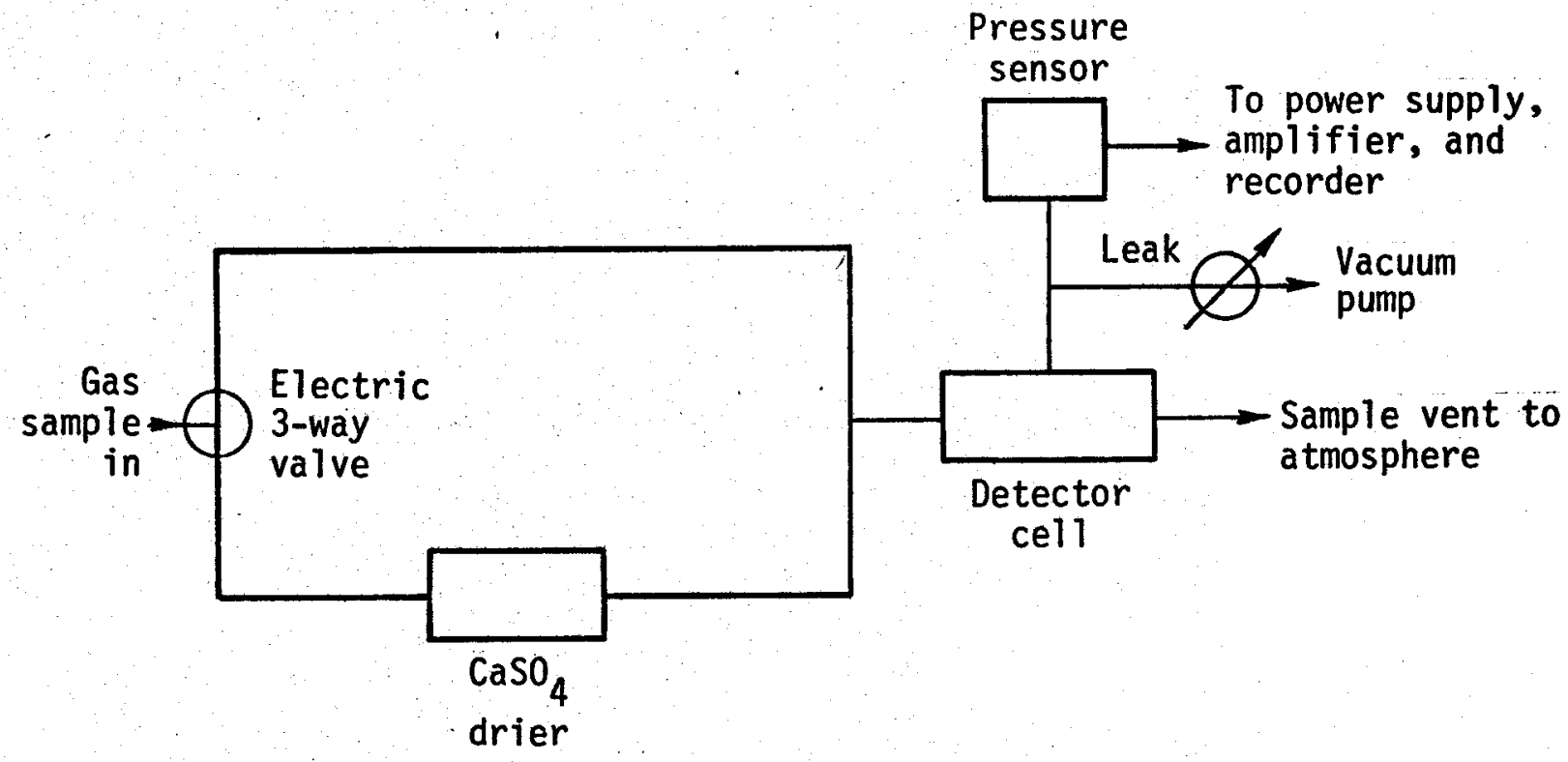

Fig. 9. Schematic diagram of water monitor.

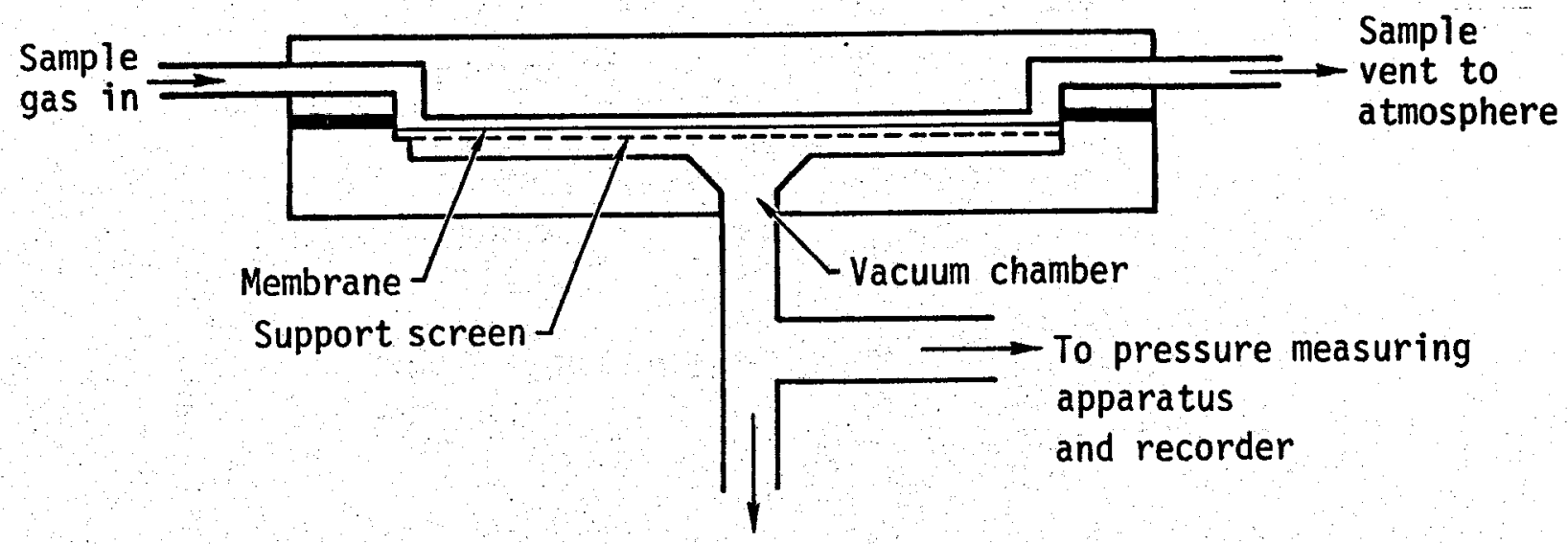

To vacuum pump

Fig. 10. Pressure-sensitive membrane detector cell. 
corresponding loss in sensitivity and response time at the higher pressures. All of the components in the flow system, up to and including the detector cell; must be heated to a temperature above that of the maximum water saturation temperature expected during a run to prevent water condensation. When the wet gas is passed over the membrane there is a pressure increase due to water passing through the membrane. (Water permeates the membrane approximately 75 times faster than the common components of air or other combustion products). The difference in pressure between the dry gas and the wet gas is due to water since water is the only component removed by the calcium sulfate drier.

Figure 11 is a photograph of the water monitoring system.

The instrument is calibrated by passing a gas (air, $\mathrm{N}_{2}$, etc.) of known water concentration through the detector and plotting an ordinary calibration curve. A flow rate of $400 \mathrm{~cm}^{3} / \mathrm{min}$ through the system glves a $90 \%$ signal response in approximately $5 \mathrm{~s}$ and $100 \%$ response in approximately $1 \mathrm{~min}$. The flow rate is set at the beginning of a run and is checked intermittently. The flow is not monitored continuously because the gas stream is so "dirty" that to do so would soon plug the flowrator. For this same reason, all components are mounted vertically so that the oil and smoke condensate will run down and out of the system without plugging the lines or contaminating the Barocel pressure detector. Figure 12 shows a typical readout for a varying concentration of water. This instrument has been successfully used on two inert gas $\left(\mathrm{N}_{2}\right)$ runs on the small retort. Each run was approximately $36 \mathrm{~h}$ during which the instrument operated trouble free. 


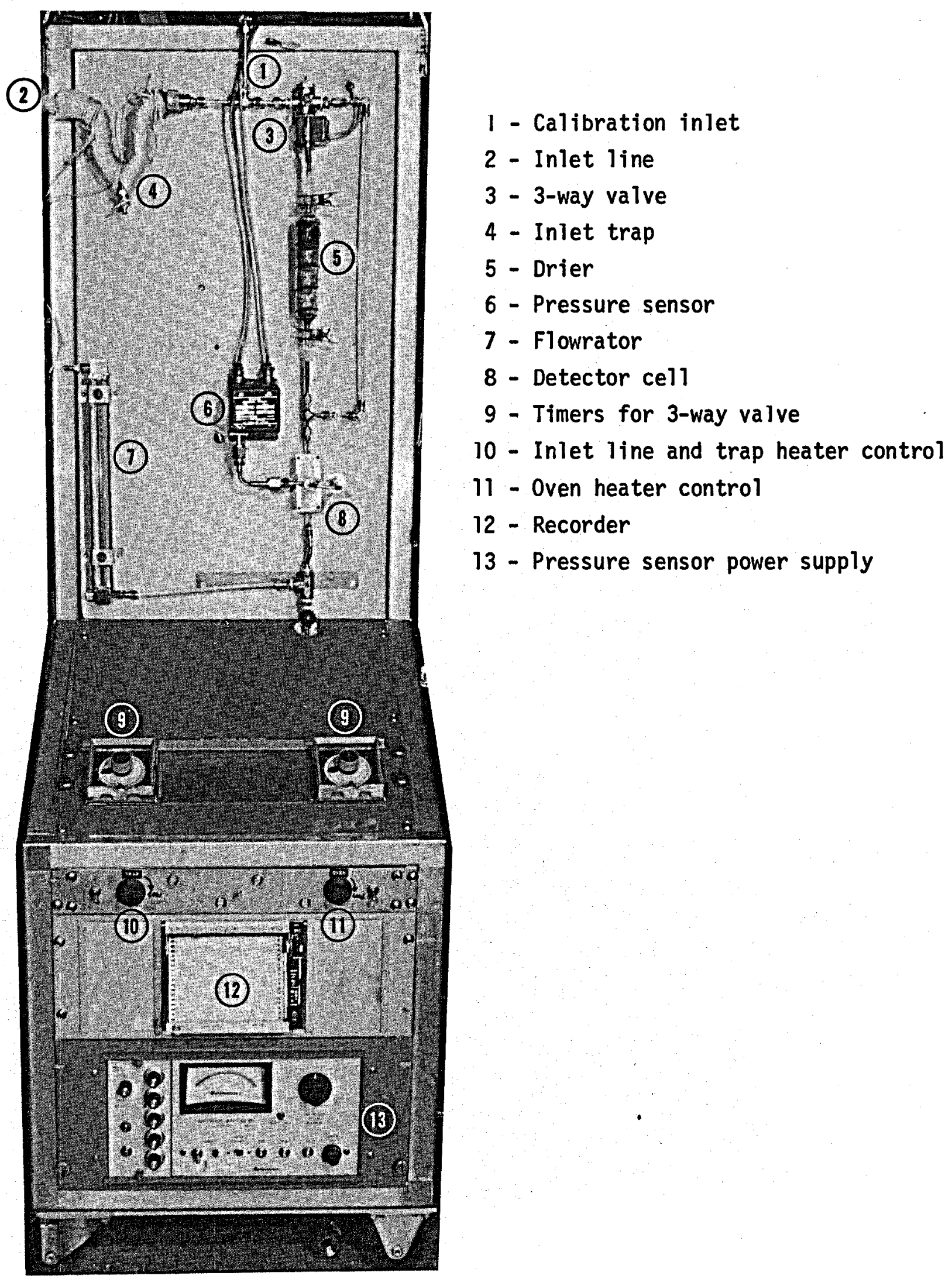

Fig. 11. Photograph of the water monitor. The top cover has been removed, 


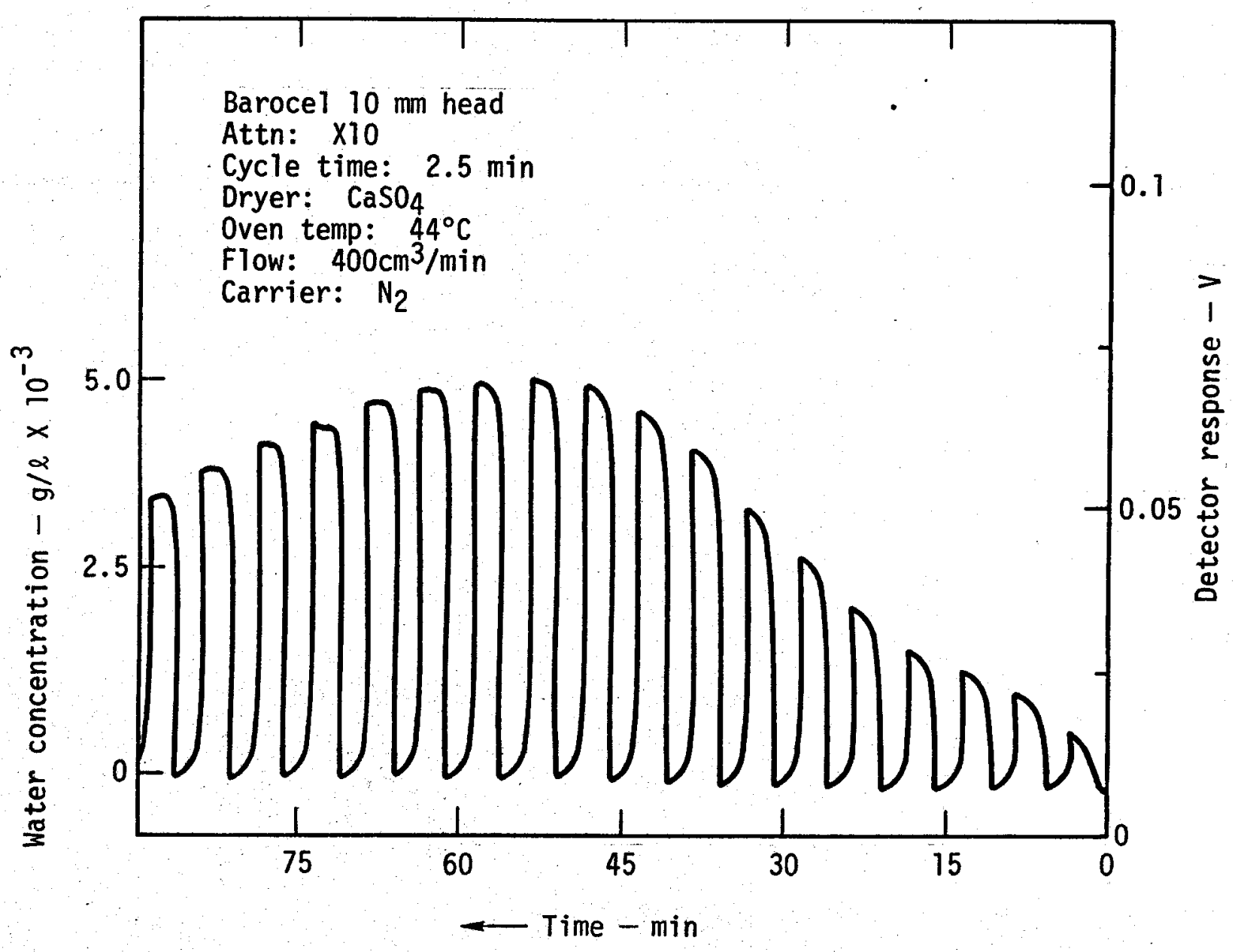

Fig. 12. Typical readout for a varying concentration of water. 